\title{
Understanding Global Citizenship: Extension Employees' Perceptions, Attitudes, and Opinions
}

\author{
Denis M. Scott \\ denis.scott@mail.wvu.edu
}

Follow this and additional works at: https://researchrepository.wvu.edu/etd

Part of the Agricultural Education Commons, and the Other Education Commons

\section{Recommended Citation}

Scott, Denis M., "Understanding Global Citizenship: Extension Employees' Perceptions, Attitudes, and Opinions" (2019). Graduate Theses, Dissertations, and Problem Reports. 3836.

https://researchrepository.wvu.edu/etd/3836

This Dissertation is protected by copyright and/or related rights. It has been brought to you by the The Research Repository @ WVU with permission from the rights-holder(s). You are free to use this Dissertation in any way that is permitted by the copyright and related rights legislation that applies to your use. For other uses you must obtain permission from the rights-holder(s) directly, unless additional rights are indicated by a Creative Commons license in the record and/ or on the work itself. This Dissertation has been accepted for inclusion in WVU Graduate Theses, Dissertations, and Problem Reports collection by an authorized administrator of The Research Repository @ WVU.

For more information, please contact researchrepository@mail.wvu.edu. 
Understanding Global Citizenship:

Extension Employees' Perceptions, Attitudes, and Opinions

Denis M. Scott

Dissertation submitted to the

Davis College of Agriculture, Natural Resources and Design

at West Virginia University

in partial fulfillment of the requirements

for the degree of

Doctor of Philosophy

in

Human and Community Development

Harry N. Boone, Jr., Ph.D., Chair

Deborah A. Boone, Ph.D.

Michael Dougherty, Ph.D.

Jean M. Woloshuk, Ed.D.

School of Design and Community Development

Morgantown, West Virginia

2019

Keywords: Extension Education, Global Citizenship, 4-H

Copyright 2019 Denis M. Scott 


\author{
ABSTRACT \\ Understanding Global Citizenship: \\ Extension Employees’ Perceptions, Attitudes, and Opinions
}

Denis M. Scott

Extension services at land-grant universities typically deliver different aspects of global citizenship education for youth through a variety of activities and instructional methods. An examination of the literature reveals that although gaps in content areas and barriers to programming do exist, there are many types of experiences available in multiple settings for youth to learn about global citizenship. These activities vary in terms of content topics, duration, and delivery methods. The purpose of the study is to determine Extension employees’ perceptions about global citizenship education, their attitudes about what content students should learn, their opinions about how they learn about global citizenship, their feelings about the barriers and program strategies for implementing global citizenship education, and their past international experiences. The study was limited to Extension employees at eight land-grant universities in four states in the Eastern United States: Kentucky, Ohio, Virginia, and West Virginia. A descriptive research design was used with an online survey divided into four major categories consisting of 10-15 questions centered on broad themes. A majority of respondents felt that they understood the concept of global citizenship and agreed that it should be an important part of the programming they deliver to youth. Significantly fewer individuals felt that that they had access to the necessary curriculum to effectively teach this topic. Some recommendations to address these concerns include developing new educational materials, promoting current Extension global citizenship curricula, and training Extension employees in methods to incorporate a global citizenship perspective into their existing lessons and programming. 


\section{DEDICATION}

To all of my friends and family, from the past and present, for giving me the future. Most of all to the star, sun, and moon. I am eternally grateful to the lucky seven for bringing peace and unconditional support while showing the value of soul and laughter. 


\section{ACKNOWLEDGEMENTS}

I would like to acknowledge the survey respondents who took time to share their insights and feedback in order to make this study possible. I am extremely appreciative of the advice and guidance of my committee members Dr. Deborah A. Boone, Dr. Michael Dougherty, and Dr. Jean M. Woloshuk throughout the entire process. Finally, I must acknowledge the consistent mentoring, ceaseless support, and endless patience of my advisor, Dr. Harry N. Boone. Thank you for being a role model in research and kindness. 


\section{TABLE OF CONTENTS}

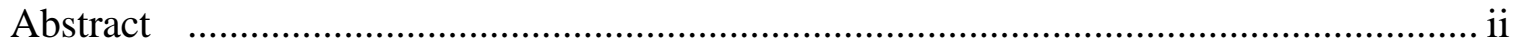

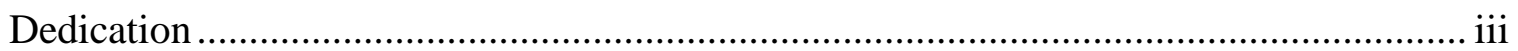

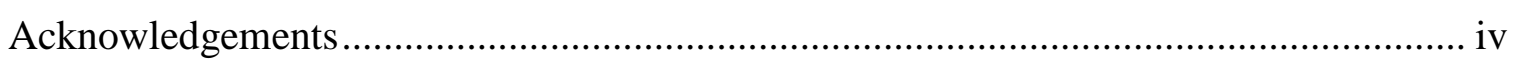

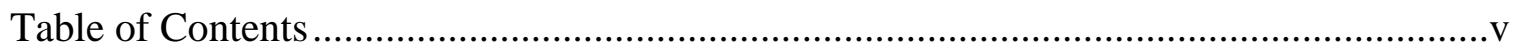

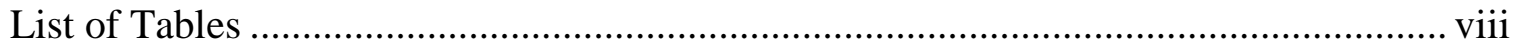

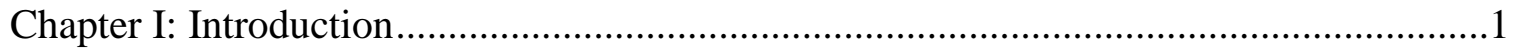

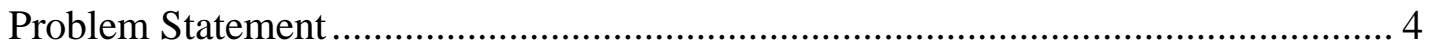

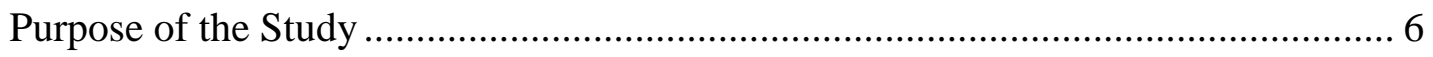

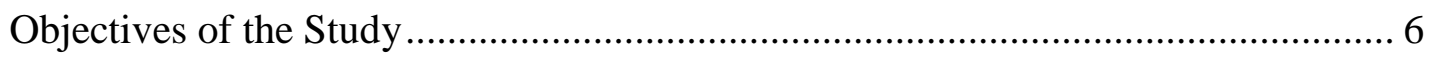

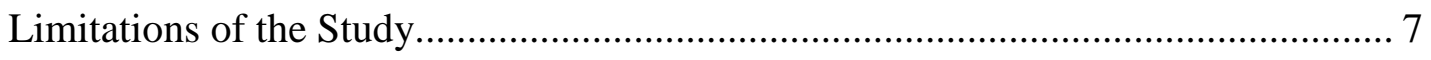

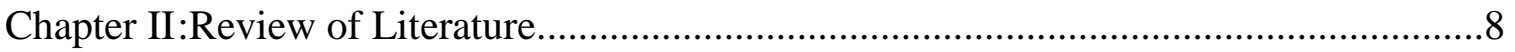

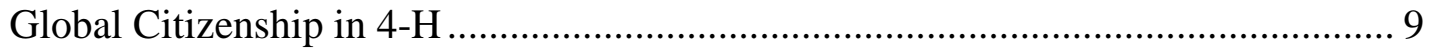

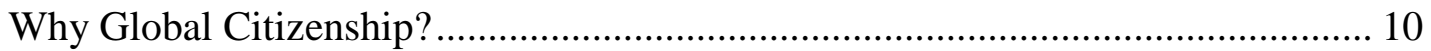

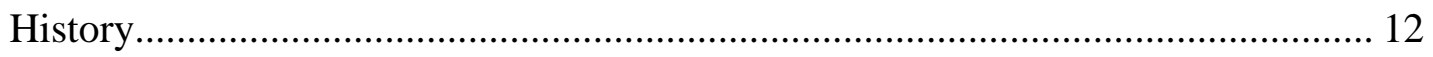

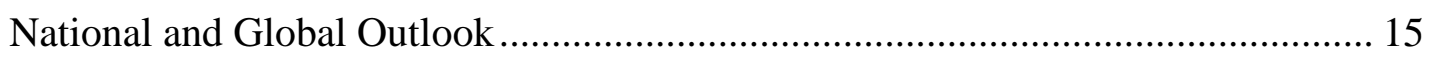

Identifying Gaps and Barriers to Globalization .................................................... 16

Types of International Programming in Extension ............................................... 17

Attitudes about International Programs .............................................................. 23

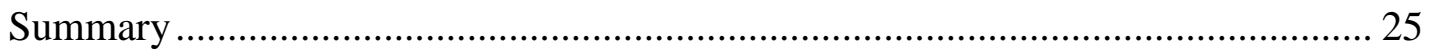

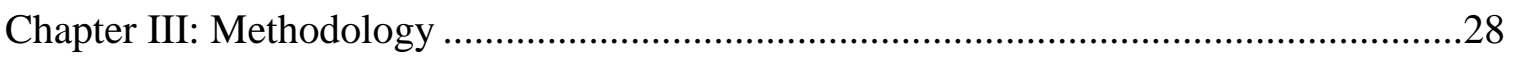

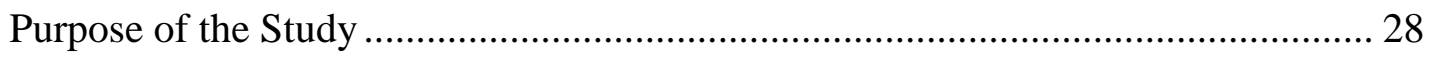

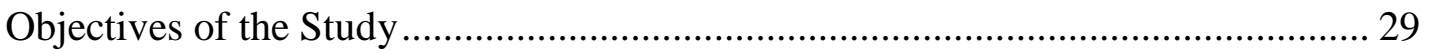

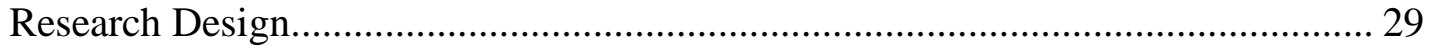

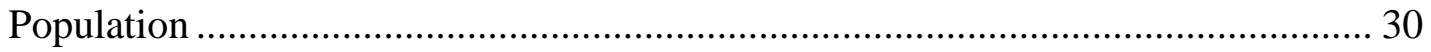

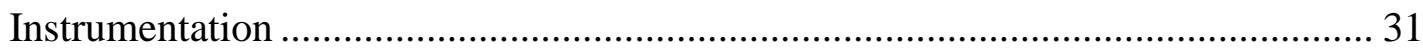

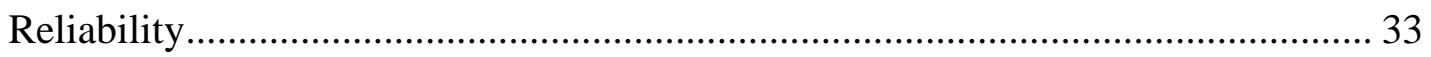

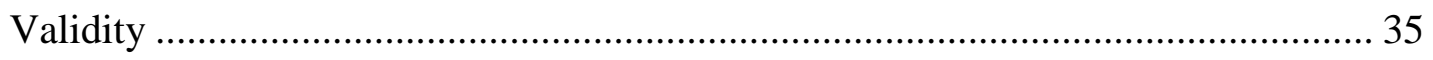

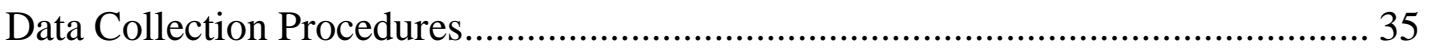

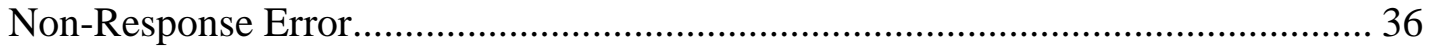

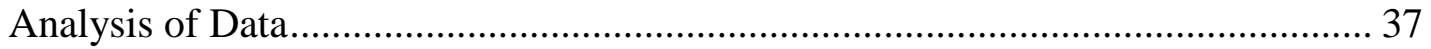

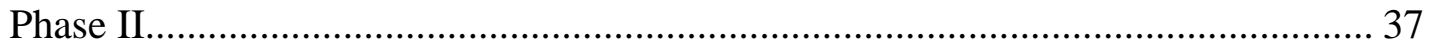




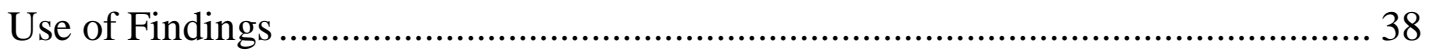

Chapter IV: Findings....................................................................................................

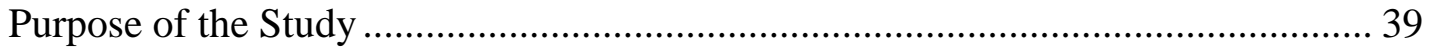

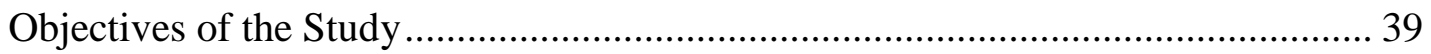

Do You Work with Youth Programming?.................................................................... 40

What Is Your Primary Responsibility? ................................................................... 41

What Is Your Race? ............................................................................................... 42

What Is Your Ethnicity? ....................................................................................... 42

In Which State Are You Currently Employed? ......................................................... 43

Please Indicate the Highest Degree that You Have Attained ..................................... 43

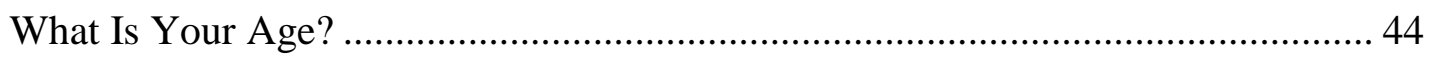

How Many Years of Experience Working with 4-H Do You Have? ......................... 45

How Many Years Have You Been Working in Your Current Position?................... 46

Were you a 4-H member as a youth?....................................................................... 47

As a Youth, Did You Participate in a 4-H Affiliated Trip Outside the Country (International Program, Exchange, States' 4-H International, IFYE, Etc.)? ............. 48

Do You Work in a Primarily Urban or Rural Area? .................................................. 48

Do You Work Primarily in a County that Is Designated as Appalachia by the Appalachian Regional Commission? ........................................................................ 49

What Is Your Primary Focus Area? ........................................................................... 49

Personal Perceptions about Global Citizenship .......................................................... 50

Supervisor Perceptions about Global Citizenship....................................................... 53

Perceptions about Curriculum and Global Citizenship............................................. 54

Attitudes about What Youth Should Learn Related To Global Citizenship.............. 56

Extension Employee Opinions about Learning Global Citizenship Through

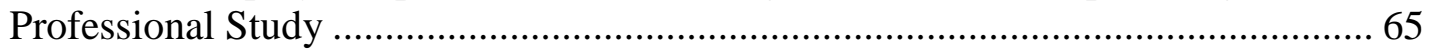

Past International Experiences of Extension Employees ............................................. 67

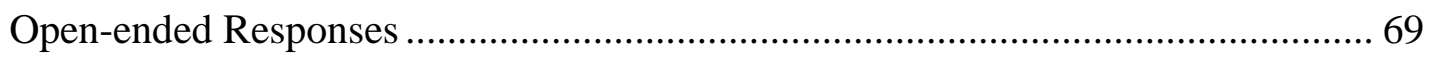

Strategies to Implement Global Citizenship Education........................................... 69

Barriers Implementing Global Citizenship Education.......................................... 71

Discriminate Analysis ........................................................................................ 72

Chapter V: Summary, Discussion, and Recommendations ...............................................75

Purpose and Objectives of the Study .................................................................... 75 


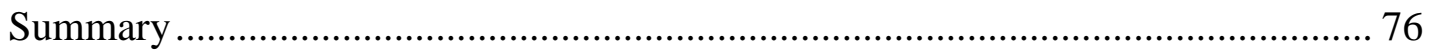

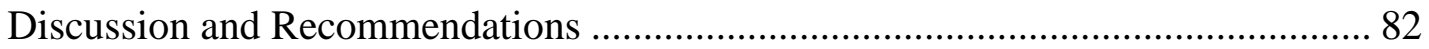

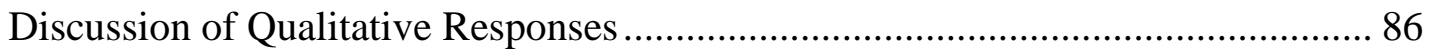

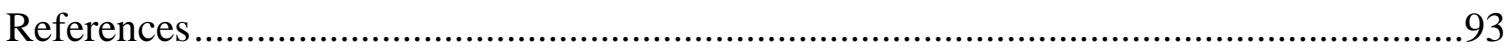

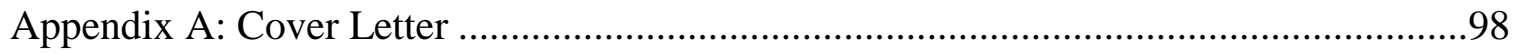

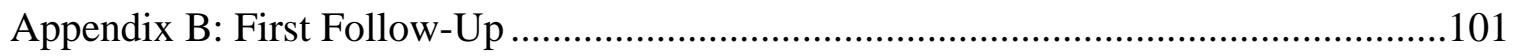

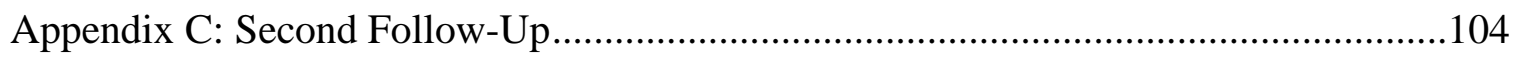

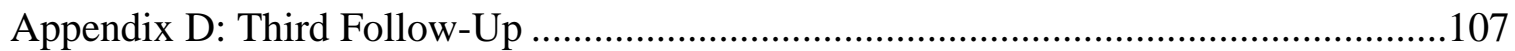

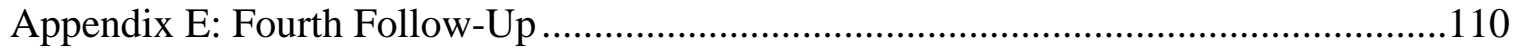

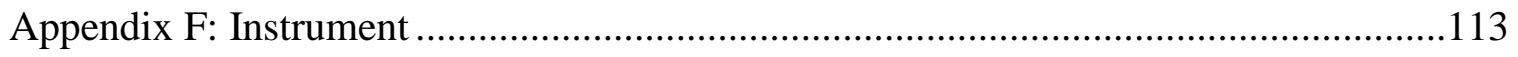

Appendix G: Responses to Open-ended Questions ..................................................119

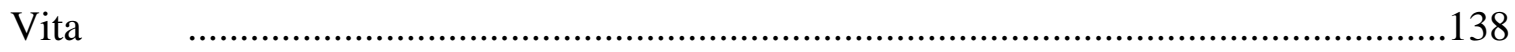




\section{LIST OF TABLES}

Table Title Page

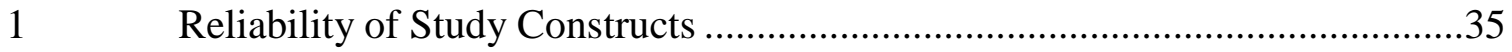

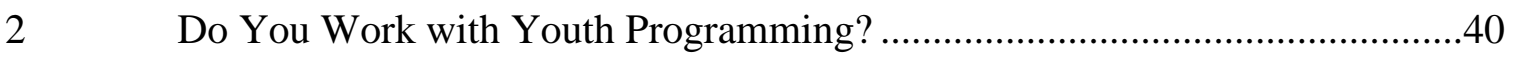

3 Respondents’ Primary Responsibility ........................................................41

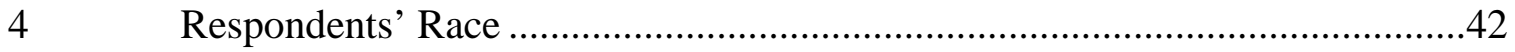

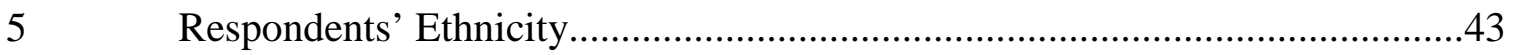

$6 \quad$ Respondents’ State of Current Employment ..................................................43

$7 \quad$ Respondents’ Education Level ..................................................................44

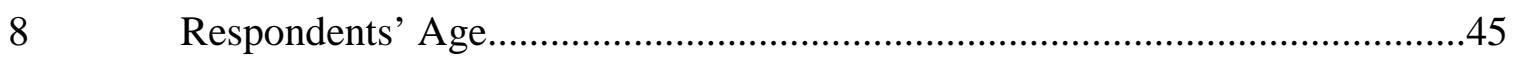

9 Respondents' Years of Experience Working With 4-H ..................................46

10 Respondents’ Number of Years in Current Position ......................................47

$11 \quad$ Were Respondents 4-H Members as Youths? ..............................................47

12 Respondents' Participation in a 4-H Affiliated Trip Outside the Country........48

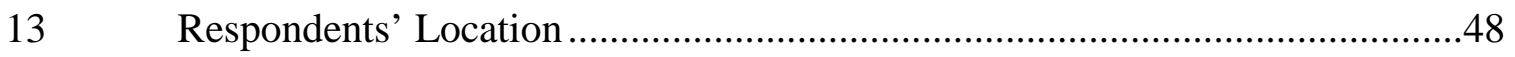

14 Do Respondents Work in Appalachia? ....................................................49

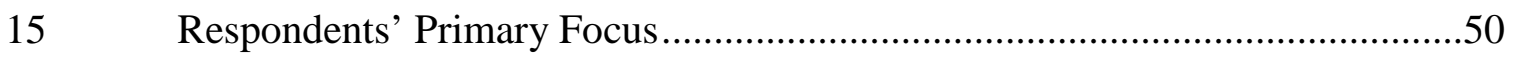

16 Personal Perceptions about Global Education...............................................52

17 Supervisors’ and Other Entities’ Perceptions About Global Citizenship .........55

18 Perceptions About Global Citizenship Curriculum.......................................57

19 Employee Attitudes About What Youth Should Learn Related to Global

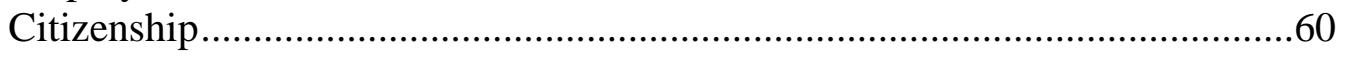

20 Extension Employee Opinions About How They Learn About Global Citizenship Through Personal Study.....

21 Extension Employees’ Opinions About Learning Global Citizenship Through Professional Study ...................................................................66

22 Past International Experiences of Extension Employees ...............................68 


\section{CHAPTER I}

\section{Introduction}

People throughout the world have become increasingly interconnected through more accessible modes of transportation, advanced communication, and computer technologies. A transatlantic crossing that took between eight to twelve weeks on a ship in the 1750s can now be accomplished in an average of six to eight hours by jet (Crilley, 2015). Similarly, conveying information by mail could take weeks or even months just a century and a half ago. The advent of the Pony Express meant that a letter could be carried from the East Coast of the United States to the West Coast in ten days. The same information today can be transmitted electronically almost instantly in the form of emails or texts, allowing for real-time exchange of ideas from anywhere on the globe.

Businesses and industries are ever more focused on internationalization and having knowledge and experience of cultures other than one's own has become a marketable skill. In previous years, individuals in the United States may have been employed by other individuals or small, local businesses, such as a town's hardware store. In contrast, an individual today may be employed by an international conglomerate.

Even individuals who have little interest in other countries and cultures may obtain employment from multi-national corporations, be affected by global market forces, food prices, energy costs or changing weather patterns, and can benefit from understanding the world through a global perspective. One researcher relayed the concept thusly: 
While everyone might continue to live their local lives, their actions made in their local environment have become global events that come back to have an impact on local spaces. Basically, whatever actions done locally, have an effect on the global landscape. For example using something as simple as sugar, can have a significant effect on the people of Brazil who produce the sugar we consume. (Lawler, 2007, p. 5)

Possessing a global perspective is increasingly important, and there are numerous opportunities and settings from which to gain such insight, and many ideas about the most effective ways for youth and adults to be taught a broadened world view through global education opportunities, classes or experiences. Skuza and Russo (2014) note that adolescence is an optimum time to engage students in youth development that focuses on attaining global citizenship. They are old enough to understand concepts, and still young and malleable enough to fully incorporate new ways of thinking and carry them into adulthood.

Extension and 4-H both have lengthy histories of contributing to the education of youth in a variety of areas, including citizenship. In the late nineteenth century, researchers found that youth were often more open to learning new concepts in agriculture than adults, and various farming clubs were formed to gather students together for the purpose of educating adolescents so that they could spread their new knowledge throughout their communities (National 4-H Council, n.d.). Citizenship has been taught in the context of 4- $\mathrm{H}$ since the inception of the organization, with particular emphasis paid through programs such as Citizenship Washington Focus, which for the last 50 years has brought youth from all over the country to Washington, D.C. to 
participate in youth development and leadership activities (National 4-H Council, 2018).

The concept of "global citizenship," however is relatively new, and these and other entities seem to be grappling with how this concept may be defined, and how best to structure and deliver programming and curricula which address the topic. Although program mandates and national mission statements ask for global education (Schillings \& Fox, 2011), these organizations have not yet fully incorporated international perspectives, or been able to provide experiences which are accessible to all members (Etling, Reaman, \& El Sawi, 1993; Ludwig, 2002b).

An examination of existing programs and curricula reveals that Extension and 4-H have been moving in some interesting and promising directions in the effort toward globalization (Ludwig, 2002a). A review of the literature also raises some questions about the need for incorporating different methods to fill some programmatic gaps, thereby complementing the work already being done (Ludwig, 1996). Although it is clear that more work is needed, what is not as immediately evident is what that work should be, and where the effort should be focused for maximum impact.

Studies suggest that one of the most important factors in transforming youth into global citizens is the attitudes of their educators (Ingram, 1999). There has been very little research on the perceptions, attitudes, and opinions of Extension employees who work with youth regarding providing education about topics with an international focus. It is not clear if a consensus exists among professionals as to the definition of global citizenship and what should be included under that subject area in related curriculum. Because there is a lack of standardization amongst the differing states’ Extension programming, there is an opportunity to examine the different methods and glean from 
them effective strategies for teaching this topic based upon the experiences of those who have done so.

A review of the spectrum of experiences and viewpoints within Extension programming delivered to youth should reveal successful strategies, as well as possible barriers to teaching global citizenship. Since Extension education was historically focused on agricultural and homemaking issues, it may be the case that some professionals in these organizations like to employ more traditional programming and are not incorporating global issues into their local educational outreach efforts. It could also be the case that instructors would be very willing to teach global citizenship, but lack curricula and knowledge of practical methods for doing so. Additionally, there may be a tendency to view global education as existing only within the narrow category of study abroad experiences, while in fact, the goal of full globalization would have a global perspective incorporated into all curricula and learning opportunities (Etling et al.).

\section{Problem Statement}

Extension Services at land-grant universities are each working on different aspects of global citizenship and these programs are delivered through a variety of activities and locations. Questions for consideration include what constitutes global citizenship education, and what does global citizenship look like within the framework Extension youth programming. A related avenue of inquiry is which of these delivery methods are best for teaching and engaging youth in global citizenship.

The National 4-H Citizenship Mission Mandate based on the Framework and Logic Models from December 2011 does not specifically mention “global citizenship,” 
however topics that are related to global citizenship are under the heading of Civic Education and subheading of Heritage, Cultural and Global Competency. This framework describes Heritage, Cultural and Global Competency as:

Heritage — movable and immovable objects of artistic, architectural, historical, archaeological, ethnographic, paleontological and geological importance.

Cultural Competency—The process of developing a set of skills that allows one to understand, value and respect one's own culture and the culture of others within the U.S. and around the world. Global Competency—The process of preparing individuals to live, work and lead in a globally interdependent world. (Schillings \& Fox, 2011, p. 2)

The framework provides a suggestion of what is indicated by "global citizenship" without fully defining the phrase. State 4-H curriculum and literature typically point to university study abroad programs or similar sources for "global citizenship” definitions. Skuza and Russo's (2014) WeConnect curriculum provides one of the few references to this exact phrase in 4-H literature and describes global citizenship as "a mindset of being responsible for people, places, and things around the world and believing that your actions impact others” (p. 64). This clearly goes beyond the traditional thinking that only when youth are studying in foreign countries are they engaged in international education, and embraces an approach in which global citizenship is enmeshed across the curriculum. 


\section{Purpose of the Study}

The purpose of the study is to determine Extension employees' perceptions about global citizenship education, Extension employees' attitudes about what content students should learn, their opinions about how they learn about global citizenship, their feelings about the barriers and program strategies for implementing global citizenship education, and their past international experiences.

Information gleaned from this study will be valuable in many ways. Assessing where Extension employees are in their own journeys toward achieving global citizenship will shed light on the current status of the initiative to produce globally competent young leaders. Additionally, knowledge about what strategies and programs are currently being used successfully should provide a springboard from which to develop new programming and curricula in the future. Identifying barriers to global citizenship education, whether stemming from policy or from individuals' biased attitudes or lack of experience may also provide insight to specific ways to resolve these and move effectively toward the goal of exposing all youth to a global perspective.

\section{Objectives of the Study}

The objectives of this study are reflected in the following research questions:

1. What are Extension employees' perceptions about global citizenship education?

2. What are Extension employees' attitudes about what content students should learn about global citizenship education?

3. What are Extension employees' opinions about how they learn about global citizenship education? 
4. What are Extension employees' feelings about barriers and program strategies for implementing global citizenship education?

5. What are Extension employees' past international experiences, and how does that impact current attitudes?

6. What characteristics can be used to discriminate between individuals with strong beliefs about global citizenship and those individuals with lesser beliefs about global citizenship?

\section{Limitations of the Study}

The study was limited to Extension employees in four states in the Eastern United States: Kentucky, Ohio, Virginia, and West Virginia. The accessible population, which was comprised of Extension employees at eight land-grant universities in four states, may not be representative of all Extension employees in the United States. 


\section{CHAPTER II}

\section{Review of Literature}

A review of the available literature on global citizenship and how Extension youth programming such as 4-H are addressing the teaching thereof, reveals some interesting and promising projects. In addition to the many strides being made in this area, there are also some gaps and opportunities for development of more programs to address this increasing need.

Even with a growing emphasis on the desire for this type of education, "global citizenship” remains a somewhat nebulous term. Zhai and Scheer (2004) define a "global perspective” as “an ecological world view which promotes the unity of humankind and the interdependence of humanity, universal human rights, loyalties that extend beyond national borders, and a future-oriented perspective” (p.39). The University of Minnesota Extension Service has produced one of the few available 4-H curricula for teaching youth global citizenship and they define the concept by first saying that citizenship is a common term that generally refers to people being engaged with their communities (Skuza \& Russo, 2014). The authors state that when citizenship is expanded to include global citizenship, "the scope of youth citizenship grows vastly and helps us reimagine the arena in which youth live, learn, work and play. Global citizenship is a continuum that ranges from being aware of the interdependent nature of our world, to understanding how local and global issues affect the lives of people around the world, to taking action to create a more equitable world” (Skuza \& Russo, 2014, p. 12). 


\section{Global Citizenship in 4-H}

4-H has a long history of teaching citizenship to youth, which is reflected in the final line of the organization’s pledge, “for my club, my community, my country, and my world” (4-H Pledge, 2018). The addition of the phrase, “my world” in 1973 indicates a move toward a global perspective (Seal, Peterson, Iwata, Kobia, \& Reddy, 2017), and a broadening of the scope of what it means to be an informed and participatory citizen in a global community. Although there is some programming that reflects this goal, researchers have noted that truly integrating a global perspective remains a challenge for 4-H clubs, potentially because of perceptions that global education must involve some form of international travel (Etling et al. 1993). This suggests a possible tendency to focus on only one specific aspect of global education while not considering the many types of programming that address other experiences and competencies, and which can be delivered without ever leaving one’s local area. Etling et al. (1993) state that: the term ‘international' should be replaced with 'global citizenship' when speaking about 4-H and youth programming. When we speak about 'global education' we should be speaking of a curriculum that helps youth gain life skills. Youth exchanges are just one activity that may comprise that curriculum. (p.2)

The National 4-H Citizenship Mission Mandate includes "Heritage, Cultural and Global Competency” under the heading of Civic Education, and defines cultural competency as, "the process of developing a set of skills that allows one to understand, value and respect one's own culture and the culture of others within the U.S. and around the world" while defining global competency as, "the process of preparing individuals to live, work and lead in a globally interdependent world” (Schillings \& Fox, 2011, p. 2). 
Although these are the stated goals of the organization, there seems to be a lack of curricula and concrete strategies as to how these objectives can be realized in real world situations, such as a local 4-H club. This may reflect a lack of a truly global perspective in Extension, 4-H’s parent organization. A survey of Extension directors in 1991 revealed that $80 \%$ of directors felt that their state had "achieved either a low level or had not achieved any level of globalization” (Ludwig, 2002b, p. 1). It could also be the case that these directors lack knowledge of what globalization entails, and therefore do not have specific strategies for achieving it.

\section{Why Global Citizenship?}

Although there is a paucity of programming and curricula that directly focuses on teaching global citizenship in Extension youth programming, there is no lack of evidence pointing to the importance of achieving this goal. The "WeConnect" curriculum states that global citizenship is a "vital aspect of developing a peaceful and prosperous human civilization” (Skuza \& Russo, 2014, p. 14). It has also been noted that gaining global experience through study-abroad programs has the power to improve students' academic skills, and can help them "learn how to solve abstract problems, work with theories, articulate their thoughts and views, cooperate with and motivate other people, plan and follow through with those plans, and develop comparative perspectives” (Connors, 2004, p. 72), all of which are laudable outcomes.

The ability to interact with diverse people, and to communicate effectively can lead to career-long advantages for people who exhibit global competency. These individuals have greater capability to "make informed decisions that link the local to the 
global and strengthen youth, families, and communities” (Treadwell, Lachapelle, \& Howe, 2013, p. 3). Students who have studied abroad are reported to have a willingness to change perspectives on global issues, and to grow from their international experiences in terms of ability to adapt to new situations and to communicate effectively (Lockett, Moore, \& Wingenbach, 2014). It should be noted that although studying abroad can be an invaluable learning experience, it is not the only way to gain cultural competency. There are myriad ways to bring global knowledge to youth within their home counties, and these provide exposure to global citizenship concepts for individuals who aren't able to travel, and may spark interest in gaining more multicultural knowledge (Seal et al., 2017).

The benefits of travel and exposure to experiences that boost cultural competency are not reserved for youth only. Extension employees who gain multicultural experience may have changes in perspective and be able to pass those along to the young people with whom they work (Ludwig, 2002a). Similarly, through international exchange programs, host families and host institutions are able to reap the benefits of exposure to someone from another culture, which results in broadened perspectives and the desire to learn more about the world and gain more global experience (Radhakrishna \& Ingram, 2005). One survey of Extension professionals found that a "reduction in prejudice," "avoidance of additional bias," and "less friction among different groups" were all seen as outcomes of education about different cultures (Ingram, 1999, p. 4).

Cultural exchanges in whatever form they occur are beneficial for the people involved, and they also create a ripple effect that is good for the world. Radhakrishna and Ingram (2005) say: 
During these times when war between and among countries has become an ongoing event, exchange programs provide positive opportunities for young people to make friends with those in other parts of the world. Additionally, our increasingly global economy will require that more and more workers of the future have the skills to relate effectively with those from other cultures. (Radhakrishna \& Ingram, 2005, p. 5)

What appears to be a simple concept is also one of profound importance, which is borne out in the literature over and over...exposure to diversity results in increased openness to diversity (Zhai \& Scheer, 2004).

\section{History}

Incorporating a global perspective into the work being done by Extension programming such as 4-H has been increasingly emphasized as the organizations grow and evolve. The Cooperative Extension System was created as a result of the SmithLever Act of 1914, providing each land-grant university with Extension workers in an effort to bring knowledge and information to the public (Daniel, Duncan, Navarro, \& Fuhrman, 2014). The act also unified disparate agricultural clubs into the national organization known as 4-H, which would operate under the auspices of Cooperative Extension (National 4-H Council, n.d.). The focus of Extension's efforts has broadened over the years from an emphasis on agriculture and farming to include solving social problems and a having a more global perspective. By 1990, the US Department of Education was expressing the need for preparing youth to function in a rapidly changing global economy, and Extension was responding (Ludwig, 1996). In 1998, Globalizing 
Agricultural Science and Educational Programs for America set a goal for agricultural colleges that included having "globally competent stakeholders, faculty, and students who live, compete, and work well in a dynamic and interdependent world community” (Ludwig, 2002b, p. 1).

The objective of globalizing Extension has obvious merits, however fully achieving this goal may remain elusive. Ludwig states that to be considered fully globalized, an Extension service must exhibit the following traits:

- Clientele understand global and national interdependencies.

- Programs stress the impact of international economic forces on agricultural markets.

- Extension professionals incorporate global concepts into ongoing Extension activities.

- The relationship between basic international issues and the Extension mission is recognized.

- Personnel evaluation systems recognize international efforts (Ludwig, 2002b, p. 2).

In a study conducted in 2000 asking Extension directors to assess the globalization of their own programming, and to compare it with previous years, results were encouraging but left much room for improvement. In 1990, there was minimal or no globalization efforts reported by 40 states, with only 9 reporting movement toward globalizing (Ludwig, 2002b). By 2000, 13 directors reported no progress or minimal progress toward globalizing, but 35 directors stated that their states were "moving in the 
direction of globalizing” (Ludwig, 2002b, p. 4). These results seem to indicate that more direction and support is needed in order to realize a fully globalized Extension Service.

4-H has followed a similar arc to its parent organization, with good progress toward incorporating a global perspective and some room for improvement remaining. As the largest organization dedicated to youth development in the United States, 4-H has the potential to impact the lives of millions of young people. The demographics of the youth served has changed greatly during the history of 4-H, with more participants living in cities, and far more racial and ethnic diversity represented in their membership. 4-H has responded by altering programming to reflect the needs of modern youth who will be leaders in a competitive global economy (Ingram, 1999).

Although it was 1973 before the 4-H pledge was altered to contain the phrase, "my world," clubs had already been formed in several countries by that point, taking the 4-H model of learning by doing to many youth around the world (Sallee \& Lancaster, 2013). This was beneficial for the international youth who participated, but did little to bring diversity or a global perspective to American youth. One of the first efforts to change that came in the form of the International Farm Youth Exchange or IFYE. This was a reciprocal cultural exchange in which youth from the United States traveled abroad for up to 6 months living on farms and learning the ways of the countries in which they lived. The name was ultimately changed to International 4-H Youth Exchange to reflect a move away from experiences that were strictly agricultural. 4-H has several other cultural exchange programs for youth, and has facilitated the hosting of tens of thousands of children and teens from Japan and other countries (Sallee \& Lancaster, 2013). 
Although Extension and 4-H have made considerable strides towards globalization, there remains much work to be done. It has been noted that international 4-H projects may be isolated from 4-H as a whole, and may lack clear direction (Sallee \& Lancaster, 2013). Stevens et al (2014) note that "In this second decade of the $21^{\text {st }}$ century, Extension still struggles with how to capitalize on the value of international experiences” (Stevens, Smith, \& Downing, 2014, p. 1).

\section{National and Global Outlook}

There is little ambiguity regarding the goal of global cultural competency when one examines recommendations from agencies such as the USDA, the US Department of Education, and others. Tritz et al. (2012) discuss the USDA's National Institute for Food \& Agriculture or NIFA's statement regarding the “importance of international research partnerships to address issues of food safety, sustainability, resource management, biotechnology and crop and livestock disease prevention” (Tritz, et al., 2012, p. 1) as an indication of the requirement for a globally competent workforce. NIFA has addressed this need by implementing The Global Thinking Academy, which is an online resource which unifies perspectives from multiple disciplines and focuses on critical thinking skills as applied to globalization efforts (Stedman, 2016).

In 2012, the US Department of Education published a document entitled, “Succeeding Globally Through International Education and Engagement,” which details

goals and objectives related to improving education in the United States regarding global issues, as well as prioritizing diplomacy with other countries (US Department of Education, 2012). As was previously discussed, both Extension and 4-H have formally 
acknowledged the need for global cultural competency in their programming, including listing "heritage, cultural and global competency" as three of the main components of civic education (Schillings \& Fox, 2011, p. 1). These are all indicators that the objective of producing globally competent citizens is acknowledged by many public and private entities, and is a recommended area of focus for US youth in general and 4-H members specifically.

\section{Identifying Gaps and Barriers to Globalization}

Since globalization is agreed to be a commendable goal, and since Extension and 4- $\mathrm{H}$ are dedicated to providing the most enriching and beneficial experiences to youth, it seems that there must be some barriers in place partially, or in some cases, fully preventing these organizations from attaining this goal. A review of the literature reveals some possible explanations and areas for improvement. One study noted that although there are many cultural exchange programs available to 4-H'ers, they may be somewhat fragmented and not well integrated into 4- $\mathrm{H}$ as a whole, as well as being prohibitively expensive for the majority of members. The authors also point out that the mere existence of such programs does not indicate the organization itself has achieved globalization (Etling et al., 1993).

Surveys of Extension professionals found that although many liked the idea of gaining international experience through travel, most felt that there were too many barriers to them doing so (Stevens et al., 2014). Some extension workers spoke of lack of time and finances keeping them from incorporating global experiences into their programming, while others stated that they were worried about the perceptions of some 
of their clientele, and were unsure as to how global citizenship fit in with other programming priorities (Ludwig, 2002a). Interestingly, worries about clientele’s opinions regarding international programs were more of a perceived barrier for directors, while the agents who deal directly with clients saw this as less of a problem (Ludwig, 2002b). This perception by directors may relate to yet another barrier to globalization, which stems from a lack of emphasis on this goal on the part of leadership. Ludwig (1996) states that, “a clear sense of direction, strong leadership in internationalizing, and enthusiasm from leaders of the organization will help to ensure concerted and sustained action” (Ludwig,1996, p. 3). The implication is that a dearth of leadership in this area could result in stagnation and a lack of meaningful progress.

In addition to barriers preventing delivery of services that focus on global citizenship, there are also gaps in this type of programming. Historically, the focus has been more on cultural exchanges in which one or a handful of students travel to a foreign country to have an immersive experience. While this is undeniably very valuable for the individuals who participate and also beneficial for all the people and entities they engage with while on these types of trips, the impact generally remains limited to this small group. Programming which is able to reach greater numbers of people, and which brings international experience and global citizenship to students who may not be able to travel abroad is needed more than ever.

\section{Types of International Programming in Extension}

An examination of the literature reveals that, although gaps and barriers do exist, there are many types of experiences available in multiple settings for youth and adults 
who wish to gain cultural competency and work toward becoming global citizens. These vary in terms of intensity, duration, intended audience, and method of delivery.

One of the most traditional, and still immensely valuable experiences is hosting a youth from a different country. These exchanges provide a fully immersive experience for the exchange student and facilitate reciprocal learning about countries and cultures for the host families and communities. It has been found that hosting a youth may have multiple impacts, including increasing the desire to host more individuals in the future, and a heightened urge to participate in international travel on the part of the host (Arnold, Davis, \& Corliss, 2014). The benefits for the youth participating in exchange programs go beyond the cultural experiences to encompass a general improvement in life skills. They usually must raise funds, which involves self-promotion, engagement with their communities, honing organizational and problem-skills, and development of leadership ability (Gillespie, 2006). One of the largest and most long-standing cultural exchanges within 4-H, and a great example of this type of experience, is the Japanese Exchange Program, which has been in place since 1972, and has engaged over 30,000 host families in the United States, and has sent more than 6,000 American 4-H'ers to Japan (Radhakrishna \& Ingram, 2005).

Immersive cultural experiences are valuable for youth and adults alike. This is especially true as the citizenry of the United States becomes more diverse, and Extension professionals are working with immigrant populations who may exist within a culture that is vastly different from the dominant culture. Having had an opportunity to visit similar cultures, and to have existed as a minority while doing so can broaden people's 
perspectives dramatically, and help them to appreciate the experience of the individuals with whom they work (Daniel et al., 2014).

The above described cultural exchanges are pinnacle experiences, and while extremely valuable, are not practical or accessible for all individuals. It has been noted that global exchanges need not involve weeks or months, but may be as simple as offering to host visiting graduate students or other international travelers for a day or even inviting them to one club meeting. This can be an eye-opening experience for older, college-bound 4-H members who had not previously seen travel through an exchange or study abroad program as an option for themselves (Ludwig, 2002a).

It has been suggested that Extension professionals can also make moves toward a more global perspective by reaching out to local ethnic communities, attending trainings on internationalizing Extension, and making contacts with international Extension agents while traveling for personal reasons or while on vacation (Harder, Lamm, \& Vergott III, 2010). Engaging in educational tours and service learning opportunities is another way for extension professionals to gain cultural competency and then share their new perspectives with local colleagues and youth (Lockett, et al, 2014). Extension professionals whose focus is agriculture and not youth development can experience growth through international experience, and this more global approach will be passed on to the young people with whom they work (Stevens et al., 2014). This is an example of truly gaining a global perspective and applying it to all facets of life, as opposed to merely teaching isolated lessons with global topics.

One innovative approach being explored as a way to bring cultural experience and awareness to those who are not able to travel is exposure to 4-H "International Villages." 
Through this approach, students are exposed to a multi-sensory experience designed to immerse them briefly in a culture other than their own. These villages are set up temporarily, and students travel from "region" to "region” tasting food, engaging in games and traditional activities and ceremonies, and learning about local cultures and customs. Knowledge of cultures is assessed before and after exposure to the International Village experience, with students showing dramatically increased scores in the areas of attitudes toward other cultures, as well as content-related knowledge (Seal, et al., 2017). Researchers noted that, "Providing cultural experiences in their home states can improve cultural knowledge and culture-related attitudes and may be a catalyst for increased interest in other internationally related programs” (Seal et al., p. 4).

Providing education and experience about the world and the people in it need not be expensive, time consuming or overly complicated. Opportunities abound for incorporating a global perspective into all programming. Etling et al. (1993) identify numerous strategies for doing this, including planning camps with this in mind, facilitating workshops and open houses which focus on global issues, engaging with sister clubs in other countries, connecting students with pen pals, studying specific countries in-depth, and showing movies and hosting speakers who will broaden students' perspectives.

The work of transforming youth into global citizens can involve myriad experiences, however one of the most basic and accessible ways to do so is with curriculum and lessons that bring the world to all students, and not just those who have the opportunity to avail themselves of travel. Extension professionals in West Virginia have developed a curriculum based around "skill-a-thons." They define a skill-a-thon as 
"an educational lesson plan that is non-competitive yet provides opportunities for the development of life skills to include: subject matter knowledge, self-awareness, decisionmaking, social interaction, and physical skills” (Tritz, et al., 2012, p. 2). These lessons cover 5 broad categories of information, which are:

- Agriculture and Food

- Arts and History

- Communication, Media and Technology

- Geography

- Global Issues

These skill-a-thons are designed to complement the curriculum in schools, while enhancing students' knowledge and improving their understanding of the world in which they live. The authors state, "Global education is no longer something that is an add-on or a luxury to be studied when time allows after 'academic subjects'. Rather, it is a necessity that can be seamlessly integrated into lessons already being taught” (Tritz, et al., 2012, p. 3).

Another significant contribution in this area is the "WeConnect" curriculum developed by University of Minnesota Extension. This is a multi-faceted set of lessons that address cultural education, $21^{\text {st }}$ century learning and global citizenship. The authors describe global citizenship as, "a continuum that ranges from being aware of the interdependent nature of our world, to understanding how local and global issues affect the lives of people around the world” (Skuza \& Russo, 2014, p. 11).

Twenty-first century learning has an emphasis on "critical thinking skills that are applied with a sense of global awareness, helping learners to be self-directed, curious, 
and creative. Effective $21^{\text {st }}$ century learners also practice higher-order thinking skills, reflecting both innovation and sound reasoning abilities” (Skuza \& Russo, 2014, p. 12). This curriculum contains strategies and methods for teaching these and other concepts which are designed to develop global citizenship in the youth of 4-H.

In conclusion, there are multiple types of international programming available to youth and adults through Extension programming such as 4-H. Outbound programs focus on sending individuals to other countries for cultural exchanges designed around building skills, gaining cultural competency, and engaging in service learning. Inbound opportunities such as States' 4-H International's Japanese hosting program provide contact with others from another culture in the setting of people's homes and 4-H clubs. The use of Global Villages fills in a gap for those students who aren’t able to physically travel to foreign destinations, but who can still experience some immersion into other cultures. Lessons and curricula are the most broadly accessible ways for educators and students to learn and gain perspective on globally related topics.

Even with the aforementioned resources and options for gaining global learning, it has been noted that Extension cannot be considered to be fully internationalized, and 4- $\mathrm{H}$ does not yet, as a whole, provide programming which fully embraces global cultural competency. This could be attributable to a variety of factors, one of which is the feelings of some individuals within those fields on the topic global education. There seems to be a gap in the literature regarding 4-H and Extension workers' understanding of what global citizenship encompasses, how they feel about their ability to deliver a global curriculum to youth, and their attitudes about doing so. 


\section{Attitudes about International Programs}

In one study which examined the experience of American agriculture students who traveled to Costa Rica, the importance of attitudes was discussed thusly, "teachers who lack awareness of other cultures may not be interested or may even resist internationalizing their agricultural instruction” (Connors, 2004, p. 72). This is supported by a study titled, "Preparing Extension Educators for a Global Community,” in which Extension workers from Purdue University were polled regarding their current involvement with international activities, and opinions regarding existing barriers and areas of possible improvement in staff development (Selby, Peters, Sammons, Branson, \& Balschweld, 2005). The researchers were able to make some recommendations based upon their findings. Considering an overall lack of international experience by respondents, the first was to increase knowledge through creative trainings which, "provide quality multicultural and international experiences for Extension educators without requiring that they leave the United States in every instance” (Selby et al., 2005, p. 8).

A second recommendation highlights the need for positive attitudes and enthusiasm about global education, stating that, "Based on another barrier identified in the study, it is clear that Extension educators do not view the international aspects of Extension as a programming priority” (Selby et al, 2005, p. 8). Recruiting a more diverse workforce and combining global competency education with leisure travel were also mentioned as strategies for bringing a more international perspective to Extension work. The authors make an important point in their summary which is that once internationalization of Extension is fully realized, “an international outlook will not be 
considered an independent focus. Instead, it will be integrated by all Extension educators into all programs areas and all programming efforts” (Selby et al., 2005, p. 8).

Etling et al. (1993) note that many people hold the opinion that 4-H programming should focus on local issues and topics, but they counter this philosophy with statistics about how many US workers are linked with foreign corporations and economies, and the need to be a competent citizen of a global community (Etling, et al., 1993). Sallee and Lancaster (2013) report that county agents place less importance on international education, and may even be resistant to such programming.

Although some individuals completely discount the importance of international education, most people do agree that it should be an integral part of Extension work and 4-H programming. A survey of Extension Agents in Florida in 2008 revealed that 76\% of respondents felt that an international Extension experience was either "somewhat important” or "very important” (Harder et al., 2010). A similar study conducted in Pennsylvania showed that over $75 \%$ of respondents "either agreed or strongly agreed that 4-H youth need to know about cultures different from their own; that learning about different cultures should be an important part of youth programs; and that 4-H should include projects that help youth learn to relate effectively with people who are different from themselves” (Ingram, 1999, p. 4).

A study of agriculture students found that teacher beliefs play a large role in determining curriculum, and these beliefs are profoundly impacted by gaining international experience. The authors stated that trust, empathy and global-mindedness were all increased when someone has been immersed in another culture (Hurst et al., 2015). Ingram (1999) discusses beliefs and perceptions thusly: 
Learning about different cultures was viewed as contributing to the overall growth and development of our youth. Experiencing different cultures can only help expand and broaden the youth person's values and growth as a human being and a well-adjusted contributing member of society. Several comments [from county Extension directors, and agents, including 4-H/youth development agents] used the term 'life skills' in reference to cultural education. Learning about other cultures was also viewed as a vehicle for gaining greater understanding and appreciation of one's own culture. (Ingram, 1999, p. 4)

\section{Summary}

Global citizenship education is a burgeoning field, and as such, is still changing and developing to meet the needs of youth. There are various approaches to teaching this topic, and multiple philosophies regarding what processes and content should be included in curriculum. While there is a nearly universal consensus amongst policy makers and Extension educators that multicultural education and global citizenship are valuable or even essential to producing culturally competent workers and members of society (Stedman, 2016), there is less agreement about how best to do this, and what exactly is entailed.

The majority of the literature on the topic focuses on going abroad to obtain experience, with much less attention paid to domestic programs and delivery methods which don't require travel. Because achieving global citizenship is a goal for all 4- $\mathrm{H}$ youth, (Schillings \& Fox, 2011) it is essential to focus on curricula and programming that can be delivered to the broadest audience, and not simply on experiences which are 
accessible to only a few students. There are a variety of approaches, including lessons such as skill-a-thons, and project books like WeConnect, immersive experiences such as global villages, as well as cultural exchanges which bring youth from other countries to the U.S. to live and interact with American young people (Radhakrishna \& Ingram, 2005; Seal et al., 2017; Skuza \& Russo, 2014; Tritz, et al., 2012). All of these are options for delivering global citizenship programming to youth who are not able to travel out of their local area.

Even with the availability of these and other programs, there seems to be a lack of unity and cohesion between different Extension offices and 4-H clubs. Some states have struggled to incorporate a global approach, and some have failed to prioritize global citizenship at all (Ludwig, 1996; Etling et al., 1993). This could be due to a variety of factors, including lack of understanding on the part of administration that global citizenship can be achieved through many more avenues than just international travel. Besides a possible lack of knowledge as to how to produce globally competent $21^{\text {st }}$ century citizens, there may also be a lack of motivation to do so, based upon employees' perceptions and opinions about global education. Studies have shown that employees' behaviors are colored by their own thoughts and experiences, and those lacking a global perspective will not be able to pass that on to their students (Connors, 2004).

A review of the literature raises numerous questions regarding approaches to teaching global citizenship, the various perceptions, attitudes, and opinions about what it means, and how best to deliver the information. Areas for further study include Extension employees’ perceptions about the definition of global education; Extension employees’ attitudes, and how having international experience can impact attitude, and 
therefore demeanor when teaching youth about global topics. There remains much work to do before Extension and 4-H can be said to be operating from a truly global perspective (Selby et al., 2005), and some more knowledge regarding personal barriers and gaps in programming will be useful to determine the best way forward for these organizations as they strive for full globalization. 


\section{CHAPTER III}

\section{Methodology}

\section{Purpose of the Study}

The purpose of this study is to explore the perceptions, attitudes, and opinions of Extension workers on the topic of global citizenship education, and the possible barriers and strategies for implementing the topic in programming. The information gathered will indicate the current thinking of those teaching in this area and will offer possible directions for delivering global citizenship programming in the future. The purpose of the study is to answer the following categories of questions, using a research design similar to the one used by Hurst et al. (2015) in their article entitled, "Beliefs and Attitudes of Secondary Agriculture Teachers about Global Agriculture Issues:” Information gleaned from this study will be valuable in many ways. Assessing where Extension employees are in their own journeys toward achieving global citizenship will shed light on the current status of the initiative to produce globally competent young leaders. Additionally, knowledge about what strategies and programs are currently being used successfully should provide a springboard from which to develop new programming and curricula in the future. Identifying barriers to global citizenship education, whether stemming from organizational focus or from individuals’ attitudes or lack of experience may also provide insight to specific ways to resolve these and move effectively toward the goal of exposing all youth to a global perspective. 


\section{Objectives of the Study}

The objectives of this study are reflected in the following research questions:

1. What are Extension employees' perceptions about global citizenship education?

2. What are Extension employees' attitudes about what content students should learn about global citizenship education?

3. What are Extension employees' opinions about how they learn about global citizenship education?

4. What are Extension employees' feelings about barriers and program strategies for implementing global citizenship education?

5. What are Extension employees' past international experiences, and how does that impact current attitudes?

6. What characteristics can be used to discriminate between individuals with strong beliefs about global citizenship and those individuals with lesser beliefs about global citizenship?

\section{Research Design}

Descriptive research has several aspects which make it appropriate for use in this study. It may be used to: "describe systematically and accurately the facts and characteristics of a given population or area of interest," to "portray the characteristics of persons, situations, or groups and the frequency with which certain phenomenon occur," and to "discover associations or relationships between or among selected variables" (Dulock, 1993, p. 154). Using the methodologies of descriptive research should reveal the correlations or lack thereof between Extensions agents' feelings toward, and 
understanding of global citizenship education and the degree to which they successfully incorporate this type of curriculum when teaching their students.

For the purpose of this study, a survey delivered through Qualtrics was used. This instrument could be received and completed by respondents electronically. Because the research focused on perceptions, attitudes, and opinions the use of a series of questions which could be answered using a Likert scale is an appropriate way to gather information, and is useful for establishing correlations between employees' feelings, and the way those are reflected in their behaviors (Boone \& Boone, 2012).

\section{Population}

The target population for this research was all Extension employees in the United States. This would include not only agents, but any professionals hired by land-grant universities who work directly with youth programs such as 4-H, including Specialists, Agents, Extension educators and other staff members. For a number of reasons, including time and resources, it was not feasible to access this entire population. For the purposes of this study, the accessible population would consist of Extension employees in West Virginia and the neighboring states of Kentucky, Ohio, and Virginia who work at land-grant universities. The land-grant universities included: West Virginia University, West Virginia State University, Virginia Polytechnic Institute and State University (Virginia Tech), Virginia State University, University of Kentucky, Kentucky State University, The Ohio State University, and Central State University (OH). In order to maximize the number of responses and provide the most complete information possible, 
surveys were sent to all individuals who met the criteria in each state. A census of the accessible population was included in the study.

\section{Instrumentation}

The instrument for this study was based upon one used by Hurst et al. (2015) in their article titled, "Beliefs and Attitudes of Secondary Agriculture Teachers About Global Agricultural Issues,” in which the authors explore agriculture educators' feelings on international issues as they relate to their prior international experience. Using the above study as a template, a survey for this study was designed, and divided into 4 major categories:

1. Extension employee perceptions about global citizenship—questions regarding understanding the definition of "global citizenship," feelings of the importance of teaching this type of material, perceived abilities to teach the topic effectively, and what types of experiences may constitute a "global citizenship experience.”

2. Extension employee attitudes about what youth should learn related to global citizenship—questions that address what topics should be covered in a global citizenship curriculum.

3. Extension employee opinions about how they learn about global citizenshipquestions about preferred delivery methods for teaching global citizenship, and the types of experiences that can contribute to increasing students' knowledge in this area.

4. Past international experiences of Extension employee-these are yes/no questions designed to determine the amount and type of international experiences that 
employees possess. These range from having taken a globally focused course as a student to having lived outside the U.S. for an extended period of time.

Each category consists of 10-15 questions centered on the broad themes.

Responses in categories one through three were recorded using a Likert scale ranging from one to five, with one being "strongly disagree" and five being "strongly agree." For the fourth group of questions, which address past international experiences of employees, the questions were also phrased in such a way as to be answerable with only one response on the Likert scale.

A fifth category consisting of demographic information was utilized. The demographic questions asked for responses about gender, state in which respondents work, educational attainment, years of experience working with 4-H, and whether or not the respondent was a 4-H member as a youth.

Although the survey was sent to all Extension employees whose email addresses had been obtained from the listserv, the first question asked whether respondents worked with youth. Participants who answered "no" were directed to the end of the survey, while participants who answered "yes" completed the survey, and their responses are discussed in the "findings" section of this document.

To be able to project the findings unto a wider population, four common frame errors were addressed. Sampling error: The researcher used a census of all Extension employees from the states surveyed. Frame: The researcher used official lists from the university Extension offices. Selection: Using the features of Excel, the researcher made sure there were no duplicates. Measurement: The instrument was determined to be valid and reliable. 


\section{Reliability}

In order to determine the reliability of the instrument, questions were grouped into six composite categories, comprised of at least four questions from each domain. The categories used were "personal perceptions” which examined respondents' knowledge and ideas about what constitutes global citizenship, “attitudes about curriculum,” which looked at respondents’ attitudes about whether they had sufficient curriculum to teach global citizenship, “feelings about supervision” which encompassed respondents’ feelings about administration as well as other stakeholders, “attitudes about global citizenship," which looked at which topics and concepts respondents thought should be included in global citizenship education, “opinions about learning through personal study” which looked at ways respondents had improved their global citizenship knowledge through means such as vacations or reading etc., and “opinions about learning through professional study” which encompassed such modes of learning as taking college classes or taking part in professional workshops.

For the category assessing personal perceptions, the data for questions 1, 2, 3, 12, 13 and 14 from section one, titled “Extension Employees’ Perceptions about Global Citizenship” was used. For the curriculum category, questions 5, 6, 7 and 15 from section one were examined. For the category assessing feelings about supervision, questions used were 4, 8, 9, 10 and 11 from section one. For the category looking at attitudes about global citizenship, questions 1-11 from the section of the instrument titled “Extension Employee Attitudes about What Youth Should Learn Related to Global Citizenship” were used. For the category about employees’ experience learning through personal study, questions 1, 6, 7, 8 and 9 from the section of the instrument titled 
“Extension Employee Opinions About How They Learn About Global Citizenship” were examined, and for the category regarding learning through professional study, questions 2, 3, 4 and 5 from the same section were used.

Results from each composite category were analyzed, and reliability was determined with the Cronbach's Alpha statistic. For the six questions that comprise the Personal Beliefs section, Cronbach’s Alpha was .779. For the four questions in the Curriculum section, Cronbach's Alpha was .793. For the five questions in the composite category regarding supervision, Cronbach’s Alpha was .762. For the 11 questions regarding employee attitudes, Cronbach’s Alpha was .898. For the eight items addressing personal study, Cronbach’s Alpha was .811. For the four items in the composite category looking at professional study, Cronbach’s Alpha was .642.

When assessing internal consistency of an instrument, an average Cronbach's Alpha score of .6 or above is considered to indicate acceptable internal consistency (Robinson, Shaver, \& Wrightsman, 1991). Although this is a new instrument, all composite categories had a Cronbach’s Alpha above .6, with most categories scoring between .7 and .9, so the instrument was determined to be reliable, which was sufficient to proceed with the study (see Table 1). 
Table 1

Reliability of Study Constructs

\begin{tabular}{lcc}
\hline \multicolumn{1}{c}{ Construct } & Cronbach's Alpha & Criterion Rating $^{1}$ \\
\hline Personal Beliefs & .779 & Extensive \\
Curriculum & .793 & Extensive \\
Supervision & .762 & Extensive \\
Employee Attitudes & .898 & Exemplary \\
Personal Study & .811 & Exemplary \\
Professional Study & .642 & Moderate \\
\hline
\end{tabular}

${ }^{1}$ Robinson, Shaver, \& Wrightsman, (1991).

\section{Validity}

A panel of experts was used to establish content and face validity of the instrument. In this case, the dissertation committee served as the panel of experts and was comprised of educators in the field of Agriculture and Extension Education. The committee has extensive experience in Extension Education. The experts determined that the questions were appropriate for assessing relevant areas regarding the concept of global citizenship, and that the instrument subjectively appeared to effectively address the stated aims of the study, and thus the instrument was deemed to exhibit face and content validity.

\section{Data Collection Procedures}

Using data collection protocols suggested by Dillman, Smyth, \& Christian (2009) the researcher used five email contacts to elicit survey responses from the target 
population. On February $4^{\text {th }}$ a cover letter linked to a Qualtrics Internet-based survey was emailed to all participants. Seven days later a reminder request about the survey was emailed. On February $15^{\text {th }}$ a second friendly reminder request was sent to individuals on the lists of Extension employees in the four selected states who had not responded. A third follow up email was sent five days later on February $20^{\text {th }}$. A final request was sent on February $25^{\text {th }}$ to all non-respondents. To address non-response error the researcher compared early to late respondents. The Extension employees contacted with the survey were given an initial deadline to reply. All responses that came in before the initial deadline were considered early. All responses that came in after the initial deadline were considered late and put into a separate group. Both the early and late groups were compared to see if there were any important differences between the groups.

\section{Non-Response Error}

In order to account for non-response error, early responders were compared with late responders. Because late responders are most similar to non-responders, (Dillman et al., 2009) if there is no significant difference between early and late responders it can be assumed that the results are broadly generalizable to the total group. If, however, there is a significant difference between early and late responders, then results may be only generalizable within the research population.

In this case, scores for each composite group of questions were compared between early and late responders. A t-test was run and revealed statistically significant differences between the early and late responders’ scores in three categories: personal perceptions, attitudes about curriculum, and feelings about supervisors. Because of this 
finding, the results from the study may be considered to be generalizable to the research population, but not universally to Extension employees who work with youth.

\section{Analysis of Data}

Information from the questionnaire was collected and entered into the SPSS

program for windows. The alpha level of significance was set $a$ priori at $\alpha \leq .05$ for all statistical tests. Descriptive analyses appropriate for the respective scales of measurement were performed on the data including measures of central tendency (mean, median, or mode) and variability (frequencies or standard deviation). The results were represented as frequencies and percentages as well as mean, median and mode in both table and narrative form.

\section{Phase II}

The responses to the six questions concerning personal perceptions about global citizenship were averaged. If the individual average scores exceeded 5.49 on the six items, the individual was classified as a global citizen. If the individual composite scores were 5.49 or less on the six items, the individual was not classified as a global citizen. Using "past international experiences” and demographic characteristics, step-wise discriminant analysis was used to identify the factors that discriminated between the global citizens and the non-global citizens. The results of the analysis will allow the researcher to recommend a set of experiences that an Extension agent will need to improve their global citizenship perspective. 


\section{Use of Findings}

Generic data will be provided to Extension administrators and used to guide future professional development. Information about the kinds of experiences which enhance global citizenship can be used when developing curriculum for youth. Findings about Extension employees’ perceptions about global citizenship education, their attitudes about what youth should learn, and insight into how they have increased their own global knowledge can contribute to the creation of programming which infuses a global citizenship perspective across the curriculum. Identifying barriers to global citizenship education, as well as strategies for overcoming these barriers will be useful when implementing effective programming for youth. 


\section{CHAPTER IV}

\section{Findings}

\section{Purpose of the Study}

The purpose of the study is to determine Extension employees' perceptions about global citizenship education, Extension employees’ attitudes about what content students should learn, their opinions about how they learn about global citizenship, their feelings about the barriers and program strategies for implementing global citizenship education, and their past international experiences.

Information gleaned from this study will be valuable in many ways. Assessing where Extension employees who work with youth (henceforth referred to as Extension employees) are in their own journeys toward achieving global citizenship will shed light on the possible professional development needs in efforts to produce globally competent youth. Additionally, knowledge about what strategies and programs are currently being used successfully should provide a springboard from which to develop new programming and curricula in the future. Identifying barriers to global citizenship education, whether stemming from policy or from individuals' biased attitudes or lack of experience may also provide insight to specific ways to resolve these and move effectively toward the goal of exposing all youth to knowledge that increases global perspective.

\section{Objectives of the Study}

The objectives of this study are reflected in the following research questions:

1. What are Extension employees’ perceptions about global citizenship education? 
2. What are Extension employees' attitudes about what content students should learn about global citizenship education?

3. What are Extension employees’ opinions about how they learn about global citizenship education?

4. What are Extension employees’ feelings about barriers and program strategies for implementing global citizenship education?

5. What are Extension employees' past international experiences, and how does that impact current attitudes?

6. What characteristics can be used to discriminate between individuals with strong beliefs about global citizenship and those individuals with lesser beliefs about global citizenship?

\section{Do You Work with Youth Programming?}

Respondents were asked if they work with youth programming. Four hundred seventy-eight respondents (61.52\%) indicated that they did and 299 (38.48\%) answered that they did not (see Table 2). Individuals who responded they did not work with youth programming were thanked for participating in the research study and directed to the exit point of the questionnaire.

Table 2

Do You Work with Youth Programming?

\begin{tabular}{lcc}
\hline & $\mathrm{f}$ & $\%$ \\
\hline Yes & 478 & 61.52 \\
No & 299 & 38.48 \\
\hline
\end{tabular}




\section{What Is Your Primary Responsibility?}

Respondents were asked to choose from a list of roles which best described their primary responsibility. Responses were divided between male and female respondents. Of those who indicated working in program support, seven (5.34\%) were male and 124 (94.66\%) were female. Of those who indicated working as county agents, 44 (26.67\%) were male and 121 (73.33\%) were female. Of those who indicated working as an area or district agent, two (33.33\%) were male and four (66.67\%) were female. Of those who indicated working as state specialists, 11 (42.31\%) were male and 15 (57.69\%) were female. Of those who indicated working in administration, ten (58.82\%) were male and seven (41.18\%) were female. In total there were 74 male respondents (21.45\%) and 271 female respondents (78.55\%) (see Table 3).

Table 3

Respondents’ Primary Responsibility

\begin{tabular}{lcccc}
\hline & \multicolumn{3}{c}{ Male } & \multicolumn{3}{c}{ Female } \\
\cline { 2 - 5 } & $\mathrm{f}$ & $\%$ & $\mathrm{f}$ & $\%$ \\
\hline Program support & 7 & 5.34 & 124 & 94.66 \\
County Agent & 44 & 26.67 & 121 & 73.33 \\
Area or District Agent & 2 & 33.33 & 4 & 66.67 \\
State Specialist & 11 & 42.31 & 15 & 57.69 \\
Administration & 10 & 58.82 & 7 & 41.18 \\
Total & 74 & 21.45 & 271 & 78.55 \\
\hline
\end{tabular}




\section{What Is Your Race?}

The American Indian or Alaskan Native category had zero respondents. The Asian category had three respondents (0.8\%). The Black or African American category had 16 respondents (4.6\%). The Native Hawaiian or Other Pacific Islander category had zero respondents. The White category had 325 respondents (93.4\%). The Other (please specify) category had four respondents (1.1\%) (see Table 4).

Table 4

Respondents’ Race

\begin{tabular}{lcc}
\hline & $\mathrm{f}$ & $\%$ \\
\hline American Indian or Alaska Native & 0 & 0.0 \\
Asian & 3 & 0.8 \\
Black or African American & 16 & 4.6 \\
Native Hawaiian or Other Pacific Islander & 0 & 0.0 \\
White & 325 & 93.4 \\
Other (Please specify) & 4 & 1.1 \\
\hline
\end{tabular}

\section{What Is Your Ethnicity?}

Respondents were asked to describe their ethnicity using the categories Hispanic or Non-Hispanic. Five (1.46\%) indicated Hispanic, and 338 (98.54\%) indicated NonHispanic (see Table 5). 
Table 5

Respondents' Ethnicity

\begin{tabular}{lcc}
\hline & $\mathrm{f}$ & $\%$ \\
\hline Hispanic & 5 & 1.46 \\
Non-Hispanic & 338 & 98.54 \\
\hline
\end{tabular}

\section{In Which State Are You Currently Employed?}

Respondents were asked in which state they were employed. Possible responses were Kentucky, Ohio, Virginia, and West Virginia. Eighty-eight respondents (25.29\%) indicated Kentucky, 118 (33.91\%) indicated Ohio, 57 (16.38\%) indicated Virginia, and 85 (24.43\%) indicated West Virginia (see Table 6).

Table 6

Respondents' State of Current Employment

\begin{tabular}{lcc}
\hline & $\mathrm{f}$ & $\%$ \\
\hline Kentucky & 88 & 25.29 \\
Ohio & 118 & 33.91 \\
Virginia & 57 & 16.38 \\
West Virginia & 85 & 24.43 \\
\hline
\end{tabular}

\section{Please Indicate the Highest Degree that You Have Attained}

Respondents were asked to indicate their highest level of education attained. Zero (.00) respondents indicated having less than a high school diploma. Forty-three (12.72\%) indicated having a high school diploma or equivalent. Ninety-one (26.92\%) indicated 
having a bachelor's degree. One hundred seventy-seven (52.37\%) indicated having a master's degree. Twenty-seven (7.99\%) indicated having a doctoral degree (see Table 7).

Table 7

Respondents' Education Level

\begin{tabular}{lcc}
\hline & $\mathrm{f}$ & $\%$ \\
\hline Less than a high school diploma & 0 & .00 \\
High school diploma or equivalent & 43 & 12.72 \\
Bachelor's degree & 91 & 26.92 \\
Master's degree & 177 & 52.37 \\
Doctoral degree & 27 & 7.99 \\
\hline
\end{tabular}

\section{What Is Your Age?}

Respondents were asked to report their age using ten-year increment categories. Zero (.00\%) indicated being under twenty, 43 (12.39\%) indicated being 21-30, 82 (23.63\%) indicated being 31-40, 97 (27.95\%) indicated being 41-50, 90 (25.94\%) indicated being 51-60, and 35 (10.09\%) indicated being 61 and over (see Table 8). 
Table 8

Respondents’ Age

\begin{tabular}{lcc}
\hline & $\mathrm{f}$ & $\%$ \\
\hline Under 20 & 0 & .00 \\
$21-30$ & 43 & 12.39 \\
$31-40$ & 82 & 23.63 \\
$41-50$ & 97 & 27.95 \\
$51-60$ & 90 & 25.94 \\
61 and over & 35 & 10.09 \\
\hline
\end{tabular}

\section{How Many Years of Experience Working with 4-H Do You Have?}

Respondents were asked to report the length of time in years that they have worked with 4-H. Forty respondents (11.80\%) indicated less that one year's experience, 80 respondents (23.60\%) indicated one to five years, 55 respondents (16.22\%) indicated six to ten years, $58(17.11 \%)$ indicated 11 to 15 years, $36(10.62 \%)$ indicated 16 to 20 years, 28 (8.26\%) indicated 21 to 25 years, and 42 (12.39\%) indicated over 25 years (see Table 9). 
Table 9

Respondents' Years of Experience Working With 4-H

\begin{tabular}{lcc}
\hline & $\mathrm{f}$ & $\%$ \\
\hline Less than one year & 40 & 11.80 \\
$1-5$ years & 80 & 23.60 \\
$6-10$ years & 55 & 16.22 \\
$11-15$ years & 58 & 17.11 \\
$16-20$ years & 36 & 10.62 \\
$21-25$ years & 28 & 8.26 \\
Over 25 years & 42 & 12.39 \\
\hline
\end{tabular}

\section{How Many Years Have You Been Working in Your Current Position?}

Respondents were asked the number of years they have worked in their current position. Forty-five respondents (12.97\%) indicated less than one year, 125 respondents (36.02\%) indicated one to five years, 62 respondents (17.87\%) indicated six to ten years, 50 respondents $(14.41 \%)$ indicated 11 to 15 years, 25 respondents $(7.20 \%)$ indicated 16 to 20 years, 21 respondents (6.05\%) indicated 21 to 25 years, and 19 respondents $(5.48 \%)$ indicated over 25 years (see Table 10) 
Table 10

Respondents’ Number of Years in Current Position

\begin{tabular}{lcc}
\hline & $\mathrm{f}$ & $\%$ \\
\hline Less than one year & 45 & 12.97 \\
$1-5$ years & 125 & 36.02 \\
$6-10$ years & 62 & 17.87 \\
$11-15$ years & 50 & 14.41 \\
$16-20$ years & 25 & 7.20 \\
$21-25$ years & 21 & 6.05 \\
Over 25 years & 19 & 5.48 \\
\hline
\end{tabular}

Were you a 4-H member as a youth?

Respondents were asked if they were members of 4-H while growing up. One hundred ninety-eight (56.73\%) answered “yes” and 151 (43.27\%) answered "no” (see Table 11).

Table 11

Were Respondents 4-H Members as Youths?

\begin{tabular}{lcc}
\hline & $\mathrm{f}$ & $\%$ \\
\hline Yes & 198 & 56.73 \\
No & 151 & 43.27 \\
\hline
\end{tabular}




\section{As a Youth, Did You Participate in a 4-H Affiliated Trip Outside the Country (International Program, Exchange, States’ 4-H International, IFYE, Etc.)?}

Respondents were asked if they had any international experiences as part of 4-H membership during their youth. Five respondents (2.54\%) indicated that they had, while 192 (97.46\%) indicated that they had not had international experience through 4-H (see Table 12).

Table 12

Respondents’ Participation in a 4-H Affiliated Trip Outside the Country

\begin{tabular}{lrc}
\hline & $\mathrm{f}$ & $\%$ \\
\hline Yes & 5 & 2.54 \\
No & 192 & 97.46 \\
\hline
\end{tabular}

\section{Do You Work in a Primarily Urban or Rural Area?}

Respondents were asked to describe the area in which they work as either urban or rural. Seventy-five respondents (21.87\%) indicated working in an urban area, and 268 (78.13\%) indicated working in a rural area (see Table 13).

Table 13

Respondents' Location

\begin{tabular}{lrc}
\hline & $\mathrm{f}$ & $\%$ \\
\hline Urban & 75 & 21.87 \\
Rural & 268 & 78.13 \\
\hline
\end{tabular}


Do You Work Primarily in a County that Is Designated as Appalachia by the Appalachian Regional Commission?

Given the possible responses “yes,” “no,” and “not sure,” respondents were asked to indicate if they worked in a county that is designated as part of Appalachia. One hundred sixteen (33.72\%) answered “yes,” 173 (50.29\%) answered “no,” and 55 (15.99\%) answered “not sure” (see Table 14).

Table 14

Do Respondents Work in Appalachia?

\begin{tabular}{lcc}
\hline & $\mathrm{f}$ & $\%$ \\
\hline Yes & 116 & 33.72 \\
No & 173 & 50.29 \\
Not sure & 55 & 15.99 \\
\hline
\end{tabular}

\section{What Is Your Primary Focus Area?}

Respondents were asked to indicate the primary focus of their work. One hundred seventy-nine (51.88\%) reported working in 4-H and Youth Development, five (1.45\%) reported working in Community and Economic Development, 85 (24.64\%) reported working in Families and Health, 46 (13.33\%) reported working in Agriculture and Natural Resources, and 30 (8.70\%) responded using the category “other” and were asked to specify their focus (see Table 15). 
Table 15

Respondents’ Primary Focus

\begin{tabular}{lcc}
\hline & $\mathrm{f}$ & $\%$ \\
\hline 4-H and Youth Development & 179 & 51.88 \\
Community and Economic Development & 5 & 1.45 \\
Families and Health & 85 & 24.64 \\
Agriculture and Natural Resources & 46 & 13.33 \\
Other & 30 & 8.70 \\
\hline
\end{tabular}

\section{Personal Perceptions about Global Citizenship}

Six questions were used to assess respondents’ personal perceptions about global citizenship. One respondent (.28\%) strongly disagreed with the statement that they understand the meaning of global citizenship, while six respondents (1.67\%) disagreed, 15 respondents (4.18\%) slightly disagreed, 74 respondents (20.61) slightly agreed, 192 respondents (53.48\%) agreed, 66 respondents (18.38\%) strongly agreed, and five respondents (1.39\%) answered “not applicable.”

Zero individuals (.00\%) strongly disagreed with the statement that they feel global citizenship is an important part of 4-H programming, while five respondents $(1.40 \%)$ disagreed, ten respondents (2.80\%) slightly disagreed, 60 respondents (16.81\%) slightly agreed, 186 respondents (52.20\%) agreed, 84 respondents (23.53\%) strongly agreed, and 12 respondents (3.36\%) answered "not applicable.”

Zero individuals (.00\%) strongly disagreed with the statement that global citizenship is part of the national 4-H mission mandates, while three respondents (.85\%) disagreed, 12 respondents (3.41\%) slightly disagreed, 56 respondents (15.91\%) slightly 
disagreed, 167 respondents (47.44\%) agreed, 68 respondents (19.32\%), and 46 respondents (13.07\%) answered “not applicable.”

Eighteen respondents (5.19\%) strongly agreed with the statement that they do not equate global citizenship with study abroad trips, while 53 respondents (15.27\%) disagreed, 87 respondents (25.07\%) slightly disagreed, 72 respondents (20.75\%) slightly agreed, 76 respondents (21.90\%) agreed, 21 (6.05\%) strongly agreed, and 20 respondents (5.76\%) answered “not applicable.”

Two respondents (.58\%) strongly disagreed with the statement that hosting international youth in one's home is a valuable global citizenship experience, while two respondents (.58\%) disagreed, five respondents (1.44\%) slightly disagreed, 56 respondents (16.14\%) slightly agreed, 154 respondents (44.38\%) agreed, 111 respondents (31.99\%) strongly agreed, and 17 respondents (4.90\%) answered “not applicable.”

Two respondents (.57\%) strongly disagreed with the statement that hosting international youth at 4-H camps is a valuable global citizenship experience, while two respondents (.57\%) disagreed, three respondents (.86\%) slightly disagreed, 48 respondents (13.71\%) slightly agreed, 154 respondents (44.00\%) agreed, 123 respondents (35.14\%) strongly agreed, and 18 respondents (5.14\%) answered “not applicable” (see Table 16). 
Table 16

Personal Perceptions about Global Education

\begin{tabular}{|c|c|c|c|c|c|c|c|c|c|c|c|c|c|c|}
\hline & \multicolumn{2}{|c|}{$\begin{array}{l}\text { Strongly } \\
\text { disagree }\end{array}$} & \multicolumn{2}{|c|}{ Disagree } & \multicolumn{2}{|c|}{$\begin{array}{l}\text { Slightly } \\
\text { disagree }\end{array}$} & \multicolumn{2}{|c|}{$\begin{array}{l}\text { Slightly } \\
\text { agree }\end{array}$} & \multicolumn{2}{|c|}{ Agree } & \multicolumn{2}{|c|}{$\begin{array}{l}\text { Strongly } \\
\text { agree }\end{array}$} & \multicolumn{2}{|c|}{ N/A } \\
\hline & $\mathrm{f}$ & $\%$ & $\mathrm{f}$ & $\%$ & $\mathrm{f}$ & $\%$ & $\mathrm{f}$ & $\%$ & $\mathrm{f}$ & $\%$ & $\mathrm{f}$ & $\%$ & $\mathrm{f}$ & $\%$ \\
\hline $\begin{array}{l}\text { I understand the meaning of } \\
\text { global citizenship }\end{array}$ & 1 & .28 & 6 & 1.67 & 15 & 4.18 & 74 & 20.61 & 192 & 53.48 & 66 & 18.38 & 5 & 1.39 \\
\hline $\begin{array}{l}\text { I feel global citizenship is an } \\
\text { important part of } 4-\mathrm{H} \\
\text { programming }\end{array}$ & 0 & .00 & 5 & 1.40 & 10 & 2.80 & 60 & 16.81 & 186 & 52.10 & 84 & 23.53 & 12 & 3.36 \\
\hline $\begin{array}{l}\text { Global citizenship is part of } \\
\text { the national } 4-\mathrm{H} \text { mission } \\
\text { mandates }\end{array}$ & 0 & .00 & 3 & .85 & 12 & 3.41 & 56 & 15.91 & 167 & 47.44 & 68 & 19.32 & 46 & 13.07 \\
\hline $\begin{array}{l}\text { I do not equate global } \\
\text { citizenship with study abroad } \\
\text { trips }\end{array}$ & 18 & 5.19 & 53 & 15.27 & 87 & 25.07 & 72 & 20.75 & 76 & 21.90 & 21 & 6.05 & 20 & 5.76 \\
\hline $\begin{array}{l}\text { Hosting international youth in } \\
\text { one's home is a valuable } \\
\text { global citizenship experience }\end{array}$ & 2 & .58 & 2 & .58 & 5 & 1.44 & 56 & 16.14 & 154 & 44.38 & 111 & 31.99 & 17 & 4.90 \\
\hline $\begin{array}{l}\text { Hosting international youth at } \\
\text { 4-H camps is a valuable global } \\
\text { citizenship experience }\end{array}$ & 2 & .57 & 2 & .57 & 3 & .86 & 48 & 13.71 & 154 & 44.00 & 123 & 35.14 & 18 & 5.14 \\
\hline
\end{tabular}




\section{Supervisor Perceptions about Global Citizenship}

Five statements were used to assess respondents' perceptions about their supervisors' and other entities' support and engagement regarding global citizenship. One respondent (.28\%) strongly disagreed with the statement that their administration supports global citizenship, while four respondents (1.14\%) disagreed, 16 respondents (4.55\%) slightly disagreed, 69 respondents (19.60\%) slightly agreed, 157 respondents (44.60\%) agreed, 67 respondents (19.03\%) strongly agreed, and 38 respondents (10.80\%) answered "not applicable."

Four respondents (1.15\%) strongly disagreed with the statement that their state extension service is globally engaged, while 13 respondents (3.72\%) disagreed, 17 respondents (4.87\%) slightly disagreed, 69 respondents (19.77\%) slightly agreed, 134 respondents (38.40\%) agreed, 84 respondents (24.07\%) strongly agreed, and 28 respondents (8.02\%) answered "not applicable.”

Nine respondents (2.58\%) strongly disagreed with the statement that their 4-H volunteers think global citizenship is important, while 33 respondents (9.46\%) disagreed, 65 respondents (18.62\%) slightly disagreed, 91 respondents (26.07\%) slightly agreed, 52 respondents (14.90\%) agreed, ten respondents (2.87\%) strongly agreed, and 89 respondents (25.50\%) answered “not applicable.”

Four respondents (1.14\%) strongly disagreed with the statement that their 4-H youth think global citizenship is important, while 26 respondents (7.43\%) disagreed, 50 respondents (14.29\%) slightly disagreed, 93 respondents (26.57\%) slightly agreed, 77 respondents (22.00\%) agreed, 20 respondents (5.71\%) strongly agreed, and 80 respondents (22.86\%) answered “not applicable.” 
Fifty-one respondents (14.53\%) strongly disagreed with the statement that Extension employees should focus on local issues, while 139 respondents (39.60\%) disagreed, 89 respondents (25.36\%) slightly disagreed, 32 respondents (9.12\%) slightly agreed, 18 respondents (5.13\%) agreed, three respondents (.85\%) strongly agreed, and 19 respondents (5.41\%) answered “not applicable” (see Table 17).

\section{Perceptions about Curriculum and Global Citizenship}

Respondents were asked four questions to gauge their perceptions about global citizenship curriculum. Twenty respondents (5.68\%) strongly disagreed with the statement that they have access to curriculum to teach global citizenship, while 64 respondents (18.18\%) disagreed, 40 respondents (11.36\%) slightly disagreed, 66 respondents (18.75\%) slightly agreed, 69 respondents (19.60\%) agreed, 24 respondents (6.82\%) strongly agreed, and 69 respondents (19.60\%) answered “not applicable.”

Four respondents (1.14\%) strongly disagreed with the statement that they can incorporate a global perspective in most lessons, while 22 respondents (6.27\%) disagreed, 36 respondents (10.26\%) slightly disagreed, 110 respondents (31.34\%) slightly agreed, 97 respondents (27.64\%) agreed, 29 respondents (8.26\%) strongly agreed, and 53 respondents (15.10\%) answered “not applicable.” 
Table 17

Supervisors' and Other Entities’ Perceptions About Global Citizenship

\begin{tabular}{|c|c|c|c|c|c|c|c|c|c|c|c|c|c|c|}
\hline & \multicolumn{2}{|c|}{$\begin{array}{l}\text { Strongly } \\
\text { disagree }\end{array}$} & \multicolumn{2}{|c|}{ Disagree } & \multicolumn{2}{|c|}{$\begin{array}{l}\text { Slightly } \\
\text { disagree }\end{array}$} & \multicolumn{2}{|c|}{ Slightly agree } & \multicolumn{2}{|c|}{ Agree } & \multicolumn{2}{|c|}{$\begin{array}{l}\text { Strongly } \\
\text { agree }\end{array}$} & \multicolumn{2}{|c|}{ N/A } \\
\hline & $\mathrm{f}$ & $\%$ & $\mathrm{f}$ & $\%$ & $\mathrm{f}$ & $\%$ & $\mathrm{f}$ & $\%$ & $\mathrm{f}$ & $\%$ & $\mathrm{f}$ & $\%$ & $\mathrm{f}$ & $\%$ \\
\hline $\begin{array}{l}\text { My administration } \\
\text { supports global } \\
\text { citizenship }\end{array}$ & 1 & .28 & 4 & 1.14 & 16 & 4.55 & 69 & 19.60 & 157 & 44.60 & 67 & 19.03 & 38 & 10.80 \\
\hline $\begin{array}{l}\text { My state Extension } \\
\text { service is globally } \\
\text { engaged }\end{array}$ & 4 & 1.15 & 13 & 3.72 & 17 & 4.87 & 69 & 19.77 & 134 & 38.40 & 84 & 24.07 & 28 & 8.02 \\
\hline $\begin{array}{l}\text { My 4-H volunteers thi } \\
\text { global citizenship is } \\
\text { important }\end{array}$ & 9 & 2.58 & 33 & 9.46 & 65 & 18.62 & 91 & 26.07 & 52 & 14.90 & 10 & 2.87 & 89 & 25.50 \\
\hline $\begin{array}{l}\text { My 4-H youth think } \\
\text { global citizenship is } \\
\text { important }\end{array}$ & 4 & 1.14 & 26 & 7.43 & 50 & 14.29 & 93 & 26.57 & 77 & 22.00 & 20 & 5.71 & 80 & 22.86 \\
\hline $\begin{array}{l}\text { 4-H educators should } \\
\text { focus on local issues }\end{array}$ & 51 & 14.53 & 139 & 39.60 & 89 & 25.36 & 32 & 9.12 & 18 & 5.13 & 3 & .85 & 19 & 5.41 \\
\hline
\end{tabular}


Two respondents (.57\%) strongly disagreed with the statement that they can teach global citizenship without leaving the country, while four respondents (1.14\%) disagreed, five respondents (1.42\%) slightly disagreed, 44 respondents (12.50\%) slightly agreed, 174 (49.43\%) agreed, 89 respondents (25.28\%) strongly agreed, and 34 respondents (9.66\%) answered “not applicable.”

Six respondents (1.71\%) strongly disagreed with the statement that it is the role of all 4-H educators to teach global citizenship, while 14 respondents (4.00\%) disagreed, 18 respondents (5.14\%) slightly disagreed, 115 respondents (32.86\%) slightly agreed, 122 respondents (34.86\%) agreed, 47 respondents (13.43\%) strongly agreed, and 28 respondents (8.00\%) answered “not applicable” (see Table 18).

\section{Attitudes about What Youth Should Learn Related To Global Citizenship}

Respondents were asked the degree to which they agreed with eleven statements about which aspects of global citizenship youth should learn more about. Zero respondents (.00\%) strongly disagreed with the statement that youth should learn more about their own heritages, while one respondent (.28\%) disagreed, zero respondents (.00\%) slightly disagreed, 34 respondents (9.55\%) slightly agreed, 185 respondents (51.97\%) agreed, and 136 respondents (38.20\%) strongly agreed. 
Table 18

Perceptions About Global Citizenship Curriculum

\begin{tabular}{|c|c|c|c|c|c|c|c|c|c|c|c|c|c|c|}
\hline & \multicolumn{2}{|c|}{$\begin{array}{l}\text { Strongly } \\
\text { disagree }\end{array}$} & \multicolumn{2}{|c|}{ Disagree } & \multicolumn{2}{|c|}{$\begin{array}{l}\text { Slightly } \\
\text { disagree }\end{array}$} & \multicolumn{2}{|c|}{ Slightly agree } & \multicolumn{2}{|c|}{ Agree } & \multicolumn{2}{|c|}{$\begin{array}{l}\text { Strongly } \\
\text { agree }\end{array}$} & \multicolumn{2}{|c|}{ N/A } \\
\hline & $\mathrm{f}$ & $\%$ & $\mathrm{f}$ & $\%$ & $\mathrm{f}$ & $\%$ & $\mathrm{f}$ & $\%$ & $\mathrm{f}$ & $\%$ & $\mathrm{f}$ & $\%$ & $\mathrm{f}$ & $\%$ \\
\hline $\begin{array}{l}\text { I have curriculum to } \\
\text { teach global citizenship }\end{array}$ & 20 & 5.68 & 64 & 18.18 & 40 & 11.36 & 66 & 18.75 & 69 & 19.60 & 24 & 6.82 & 69 & 19.60 \\
\hline $\begin{array}{l}\text { I can incorporate a } \\
\text { global perspective in } \\
\text { most lessons }\end{array}$ & 4 & 1.14 & 22 & 6.27 & 36 & 10.26 & 110 & 31.34 & 97 & 27.64 & 29 & 8.26 & 53 & 15.10 \\
\hline $\begin{array}{l}\text { I can teach global } \\
\text { citizenship without } \\
\text { leaving the country }\end{array}$ & 2 & .57 & 4 & 1.14 & 5 & 1.42 & 44 & 12.50 & 174 & 49.43 & 89 & 25.28 & 34 & 9.66 \\
\hline $\begin{array}{l}\text { It is the role of all } 4-\mathrm{H} \\
\text { educators to teach } \\
\text { global citizenship }\end{array}$ & 6 & 1.71 & 14 & 4.00 & 18 & 5.14 & 115 & 32.86 & 122 & 34.86 & 47 & 13.43 & 28 & 8.00 \\
\hline
\end{tabular}


Zero respondents (.00\%) strongly disagreed with the statement that youth should learn more about global issues, while zero respondents (.00\%) disagreed, zero respondents (.00\%) slightly disagreed, 35 respondents (9.86\%) slightly agreed, 186 (52.39\%) agreed, and 134 (37.75\%) strongly agreed.

Zero respondents (.00\%) strongly disagreed with the statement that youth should learn more about cultural issues, while zero respondents (.00\%) disagreed, zero respondents (.00\%) disagreed, three respondents (.84\%) slightly disagreed, 22 respondents (6.18\%) slightly agreed, 182 respondents (51.12\%) agreed, and 149 respondents (41.85\%) agreed.

Zero respondents (.00\%) strongly disagreed with the statement that youth should learn more about agriculture and food, while zero respondents (.00\%) disagreed, zero respondents (.00\%) slightly disagreed, 11 respondents (3.09\%) slightly agreed, 140 respondents (39.33\%) agreed and 205 respondents (57.58\%) strongly agreed.

Zero respondents (.00\%) strongly disagreed with the statement that youth should learn more about arts and history, while one respondent (.28\%) disagreed, three respondents (.85\%) slightly disagreed, 30 respondents (8.47\%) slightly agreed, 194 respondents (54.80\%) agreed, and 126 respondents (35.59\%) strongly agreed.

Zero respondents (.00\%) strongly disagreed with the statement that youth should learn more about communication, media and technology, while one respondent (.28\%) disagreed, three respondents (.84\%) slightly disagreed, 22 respondents (6.18\%) slightly agreed, 177 respondents (49.72\%) agreed, and 153 (42.98\%) strongly agreed.

Zero respondents (.00\%) strongly disagreed with the statement that youth should learn more about geography, while zero respondents (.00\%) disagreed, three respondents 
(.84\%) slightly disagreed, 21 respondents (5.90\%) slightly agreed, 201 respondents (56.46\%) agreed, and 139 respondents (36.80\%) strongly agreed.

One respondent (.28\%) strongly disagreed with the statement that youth should learn more about national politics, while two respondents (.56\%) disagreed, 18 respondents (5.08\%) slightly disagreed, 60 respondents (16.95\%) slightly agreed, 168 (47.46\%) agreed, 105 respondents (29.66\%) strongly agreed.

One respondent (.28\%) strongly disagreed with the statement that youth should learn more about international politics, while two respondents (.57\%) disagreed, 27 respondents (7.65\%) slightly disagreed, 67 respondents (18.98\%) slightly agreed, 172 respondents (48.73\%) agreed, and 84 respondents (23.80\%) strongly agreed.

Zero respondents (.00\%) strongly disagreed with the statement that youth should learn more about intercultural communication, while one respondent (.28\%) disagreed, two respondents (.56\%) slightly disagreed, 40 respondents (11.24\%) slightly agreed, 179 respondents (50.28\%) agreed, and 134 respondents (37.64\%) strongly agreed.

Zero respondents (.00\%) strongly disagreed with the statement that youth should learn more about diversity, while one respondent (.28\%) disagreed, zero respondents (.00\%) slightly disagreed, 27 respondents (7.61\%) slightly agreed, 139 respondents (39.15\%) agreed, and 188 respondents (52.96\%) strongly agreed (see Table 19). 
Table 19

Employee Attitudes About What Youth Should Learn Related to Global Citizenship

\begin{tabular}{|c|c|c|c|c|c|c|c|c|c|c|c|c|}
\hline & \multicolumn{2}{|c|}{$\begin{array}{l}\text { Strongly } \\
\text { disagree }\end{array}$} & \multicolumn{2}{|c|}{ Disagree } & \multicolumn{2}{|c|}{ Slightly disagree } & \multicolumn{2}{|c|}{ Slightly agree } & \multicolumn{2}{|c|}{ Agree } & \multicolumn{2}{|c|}{ Strongly agree } \\
\hline & $\mathrm{f}$ & $\%$ & $\mathrm{f}$ & $\%$ & $\mathrm{f}$ & $\%$ & $\mathrm{f}$ & $\%$ & $\mathrm{f}$ & $\%$ & $\mathrm{f}$ & $\%$ \\
\hline Their own heritages & 0 & .00 & 1 & .28 & 0 & .00 & 34 & 9.55 & 185 & 51.97 & 136 & 38.20 \\
\hline Global issues & 0 & .00 & 0 & .00 & 0 & .00 & 35 & 9.86 & 186 & 52.39 & 134 & 37.75 \\
\hline Agriculture and food & 0 & .00 & 0 & .00 & 0 & .00 & 11 & 3.09 & 140 & 39.33 & 205 & 57.58 \\
\hline Arts and history & 0 & .00 & 1 & .28 & 3 & .85 & 30 & 8.47 & 194 & 54.80 & 126 & 35.59 \\
\hline $\begin{array}{l}\text { Communication, } \\
\text { media, and technology }\end{array}$ & 0 & .00 & 1 & .28 & 3 & .84 & 22 & 6.18 & 177 & 49.72 & 153 & 42.98 \\
\hline National politics & 1 & .28 & 2 & .56 & 18 & 5.08 & 60 & 16.95 & 168 & 47.46 & 105 & 29.66 \\
\hline International politics & 1 & .28 & 2 & .57 & 27 & 7.65 & 67 & 18.98 & 172 & 48.73 & 84 & 23.80 \\
\hline $\begin{array}{l}\text { Intercultural } \\
\text { communication }\end{array}$ & 0 & .00 & 1 & .28 & 2 & .56 & 40 & 11.24 & 179 & 50.28 & 134 & 37.64 \\
\hline Diversity & 0 & .00 & 1 & .28 & 0 & .00 & 27 & 7.61 & 139 & 39.15 & 188 & 52.96 \\
\hline
\end{tabular}




\section{Extension Employee Opinions about How They Learn About Global Citizenship through Personal Study}

Respondents were asked about the ways in which they learn about global citizenship through personal study. Eleven respondents (3.16\%) strongly disagreed with the statement that they learn by watching selected television programs, while 44 respondents (12.64\%) disagreed, 38 respondents (10.92\%) slightly disagreed, 136 respondents (39.08\%) slightly agreed, 102 respondents (29.31\%) agreed, and 17 respondents (4.89\%) strongly agreed.

Forty-eight respondents (14.08\%) strongly disagreed with the statement that they learn about global citizenship by taking vacations in other countries, while 62 respondents (18.18\%) disagreed, 31 respondents (9.09\%) slightly disagreed, 60 respondents (17.60\%) slightly agreed, 89 respondents (26.10\%) agreed, and 51 respondents (14.96\%) strongly agreed.

Thirty-seven respondents (10.79\%) strongly disagreed with the statement that they learn about global citizenship by listening to selected radio programs, while 80 respondents (23.32\%) disagreed, 56 respondents (16.33\%) slightly disagreed, 89 respondents (25.95\%) slightly agreed, 64 respondents (18.66\%) agreed, and 17 respondents (4.96\%) strongly agreed.

Thirty respondents (8.67\%) strongly disagreed with the statement that they learn about global citizenship by engaging in social media, while 39 respondents $(11.27 \%)$ disagreed, 53 respondents (15.32\%) slightly disagreed, 127 respondents (36.71\%) slightly agreed, 81 respondents (23.41\%) agreed, and 16 respondents (4.62\%) strongly agreed. 
Fifty-four respondents (15.93\%) strongly disagreed with the statement that they learn about global citizenship by listening to podcasts, while 72 respondents (21.24\%) disagreed, 57 respondents (16.81\%) slightly disagreed, 78 respondents (23.01\%) slightly agree, 61 respondents (17.99\%) agreed, and 17 respondents (5.01\%) strongly agreed.

Thirty-two respondents (9.33\%) strongly disagreed with the statement that they learn about global citizenship by reading periodicals, while 43 respondents (12.54\%) disagreed, 35 respondents (10.20\%) slightly disagreed, 103 respondents (30.03\%) slightly agreed, 111 respondents (32.26\%) agreed, and 19 respondents (5.54\%) strongly agreed. Sixteen respondents (4.65\%) strongly disagreed with the statement that they learn about global citizenship by reading books, while 20 respondents (5.81\%) disagreed, 27 respondents (7.85\%) slightly disagreed, 93 respondents (27.03\%) slightly agreed, 143 respondents (41.57\%) agreed, and 45 respondents (13.08\%) strongly agreed.

Eleven respondents (3.19\%) strongly disagreed with the statement that they learn about global citizenship by having friends from other countries, while 21 respondents (6.09\%), 21 respondents (6.09\%) slightly disagree, 69 respondents (20.00\%) slightly agreed, 122 respondents (35.36\%) agreed, and 101 respondents (29.28\%) strongly agreed. 
Table 20

Extension Employee Opinions About How They Learn About Global Citizenship Through Personal Study

\begin{tabular}{|c|c|c|c|c|c|c|c|c|c|c|c|c|}
\hline & \multicolumn{2}{|c|}{$\begin{array}{l}\text { Strongly } \\
\text { disagree }\end{array}$} & \multicolumn{2}{|c|}{ Disagree } & \multicolumn{2}{|c|}{$\begin{array}{l}\text { Slightly } \\
\text { disagree }\end{array}$} & \multicolumn{2}{|c|}{ Slightly agree } & \multicolumn{2}{|c|}{ Agree } & \multicolumn{2}{|c|}{ Strongly agree } \\
\hline & $\mathrm{f}$ & $\%$ & $\mathrm{f}$ & $\%$ & $\mathrm{f}$ & $\%$ & $\mathrm{f}$ & $\%$ & $\mathrm{f}$ & $\%$ & $\mathrm{f}$ & $\%$ \\
\hline $\begin{array}{l}\text { Watching selected } \\
\text { television programs }\end{array}$ & 11 & 3.16 & 44 & 12.64 & 38 & 10.92 & 136 & 39.08 & 102 & 29.31 & 17 & 4.89 \\
\hline Professional development & 8 & 2.32 & 30 & 8.70 & 39 & 11.30 & 96 & 27.83 & 143 & 41.45 & 29 & 8.41 \\
\hline My college classes & 9 & 2.60 & 37 & 10.69 & 43 & 12.43 & 91 & 26.30 & 115 & 33.24 & 51 & 14.74 \\
\hline $\begin{array}{l}\text { Attending community } \\
\text { events such as cultural } \\
\text { festivals or shows }\end{array}$ & 6 & 1.73 & 20 & 5.76 & 33 & 9.51 & 98 & 28.24 & 141 & 40.63 & 49 & 14.12 \\
\hline $\begin{array}{l}\text { Participating in study } \\
\text { abroad programs }\end{array}$ & 65 & 19.58 & 94 & 28.31 & 28 & 8.43 & 37 & 11.14 & 52 & 15.66 & 56 & 16.87 \\
\hline $\begin{array}{l}\text { Taking vacations in other } \\
\text { countries }\end{array}$ & 48 & 14.08 & 62 & 18.18 & 31 & 9.09 & 60 & 17.60 & 89 & 26.10 & 51 & 14.96 \\
\hline
\end{tabular}


Table 20 (continued)

Extension Employee Opinions About How They Learn About Global Citizenship Through Personal Study

\begin{tabular}{|c|c|c|c|c|c|c|c|c|c|c|c|c|}
\hline & \multicolumn{2}{|c|}{$\begin{array}{l}\text { Strongly } \\
\text { disagree }\end{array}$} & \multicolumn{2}{|c|}{ Disagree } & \multicolumn{2}{|c|}{$\begin{array}{l}\text { Slightly } \\
\text { disagree }\end{array}$} & \multicolumn{2}{|c|}{ Slightly agree } & \multicolumn{2}{|c|}{ Agree } & \multicolumn{2}{|c|}{ Strongly agree } \\
\hline & $\mathrm{f}$ & $\%$ & $\mathrm{f}$ & $\%$ & $\mathrm{f}$ & $\%$ & $\mathrm{f}$ & $\%$ & $\mathrm{f}$ & $\%$ & $\mathrm{f}$ & $\%$ \\
\hline $\begin{array}{l}\text { Listening to selected radio } \\
\text { programs }\end{array}$ & 37 & 10.79 & 80 & 23.32 & 56 & 16.33 & 89 & 25.95 & 64 & 18.66 & 17 & 4.96 \\
\hline Engaging in social media & 30 & 8.67 & 39 & 11.27 & 53 & 15.32 & 127 & 36.71 & 81 & 23.41 & 16 & 4.62 \\
\hline Listening to podcasts & 54 & 15.93 & 72 & 21.24 & 57 & 16.81 & 78 & 23.01 & 61 & 17.99 & 17 & 5.01 \\
\hline Reading periodicals & 32 & 9.33 & 43 & 12.54 & 35 & 10.20 & 103 & 30.03 & 111 & 32.36 & 19 & 5.54 \\
\hline Reading books & 16 & 4.65 & 20 & 5.81 & 27 & 7.85 & 93 & 27.03 & 143 & 41.57 & 45 & 13.08 \\
\hline $\begin{array}{l}\text { Having friends from } \\
\text { different countries }\end{array}$ & 11 & 3.19 & 21 & 6.09 & 21 & 6.09 & 69 & 20.00 & 122 & 35.36 & 101 & 29.28 \\
\hline
\end{tabular}




\section{Extension Employee Opinions about Learning Global Citizenship Through Professional Study}

Respondents were asked about the degree to which they learn about global citizenship through professional study. Eight respondents (2.32\%) strongly disagreed with the statement that they learn about global citizenship through professional development, while 30 respondents (8.70\%) disagreed, 39 respondents (11.30\%) slightly disagreed, 96 respondents (27.83\%) slightly agreed, 143 respondents (41.45\%) agreed, and 29 respondents (8.41\%) strongly agreed.

Nine respondents (2.60\%) strongly disagreed with the statement that they learn about global citizenship in their college classes, while 37 respondents (10.69\%) disagreed, 43 respondents (12.43\%) slightly disagreed, 91 respondents (26.30\%) slightly agree, 115 respondents (33.24\%) agree, and 51 respondents (14.74\%) strongly agree.

Six respondents (1.73\%) strongly disagreed with the statement that they learn about global citizenship by attending community events such as cultural festivals or shows, while 20 respondents (5.76\%) disagreed, 33 respondents (9.51\%) slightly disagreed, 98 respondents (28.24\%) slightly agreed, 141 respondents (40.63\%) agreed, and 49 respondents (14.12\%) strongly agreed.

Sixty-five respondents (19.58\%) strongly disagreed with the statement that they learn about global citizenship through participating in study abroad programs, while 94 respondents (28.31\%) disagreed, 28 respondents (8.43\%) slightly disagreed, 37 respondents (11.14\%) slightly agreed, 52 respondents (15.66\%) agreed, and 56 respondents (16.87\%) strongly agreed (see Table 21 ). 
Table 21

Extension Employees’ Opinions About Learning Global Citizenship Through Professional Study

\begin{tabular}{|c|c|c|c|c|c|c|c|c|c|c|c|c|}
\hline & \multicolumn{2}{|c|}{$\begin{array}{l}\text { Strongly } \\
\text { disagree }\end{array}$} & \multicolumn{2}{|c|}{ Disagree } & \multicolumn{2}{|c|}{ Slightly disagree } & \multicolumn{2}{|c|}{ Slightly agree } & \multicolumn{2}{|c|}{ Agree } & \multicolumn{2}{|c|}{ Strongly agree } \\
\hline & $\mathrm{f}$ & $\%$ & $\mathrm{f}$ & $\%$ & $\mathrm{f}$ & $\%$ & $\mathrm{f}$ & $\%$ & $\mathrm{f}$ & $\%$ & $\mathrm{f}$ & $\%$ \\
\hline $\begin{array}{l}\text { Professional } \\
\text { development }\end{array}$ & 8 & 2.32 & 30 & 8.70 & 39 & 11.30 & 96 & 27.83 & 143 & 41.45 & 29 & 8.41 \\
\hline My college classes & 9 & 2.60 & 37 & 10.69 & 43 & 12.43 & 91 & 26.30 & 115 & 33.24 & 51 & 14.74 \\
\hline $\begin{array}{l}\text { Attending } \\
\text { community events } \\
\text { such as cultural } \\
\text { festivals or shows }\end{array}$ & 6 & 1.73 & 20 & 5.76 & 33 & 9.51 & 98 & 28.24 & 141 & 40.63 & 49 & 14.12 \\
\hline $\begin{array}{l}\text { Participating in } \\
\text { study abroad } \\
\text { programs }\end{array}$ & 65 & 19.58 & 94 & 28.31 & 28 & 8.43 & 37 & 11.14 & 52 & 15.66 & 56 & 16.87 \\
\hline
\end{tabular}




\section{Past International Experiences of Extension Employees}

Respondents were asked if they had had certain types of past experiences that relate to global citizenship. One hundred forty-eight respondents (43.53\%) indicated that they had integrated global examples or case studies in their youth curriculum. One hundred ninety-four respondents (56.73\%) indicated that they had traveled internationally for personal reasons such as vacation. One hundred eighty-nine respondents (55.10\%) indicated that they had participated in professional development workshops with a global focus. One hundred sixty-six respondents (48.54\%) indicated that they had taken a globally focused course as a student. Fifty-three respondents (15.54\%) indicated that they had participated in a short-term study abroad experience as a student lasting one to three weeks. Fifty-three respondents (15.54\%) indicated that they had participated in a short-term study abroad experience as an adult lasting one to three weeks. Thirty respondents (8.77\%) indicated that they had participated in a long-term study abroad experience as a student lasting more than three weeks. Nineteen respondents (5.54\%) indicated that they had participated in a long-term study abroad experience as an adult lasting more than three weeks. Twenty-four respondents (7.02\%) indicated that they had lived outside the U.S. for a short duration (less than a year) for personal reasons. Twenty-one respondents (6.12\%) indicated that they had lived outside the U.S. for a short duration (less than a year) for professional reasons. Nineteen respondents (5.54\%) indicated that they had lived outside the U.S. for a long duration (more than one year) for personal reasons. Finally, sixteen respondents (4.71\%) indicated that they had lived outside the U.S. for a long duration (greater that one year) for professional reasons (see Table 22). 
Table 22

Past International Experiences of Extension Employees

\begin{tabular}{|c|c|c|}
\hline & \multicolumn{2}{|c|}{ Yes } \\
\hline & $\mathrm{f}$ & $\%$ \\
\hline $\begin{array}{l}\text { Integrated global examples or case studies in } \\
\text { my youth programming }\end{array}$ & 148 & 43.53 \\
\hline $\begin{array}{l}\text { Traveled internationally for personal reasons } \\
\text { (i.e. vacation, etc.) }\end{array}$ & 194 & 56.73 \\
\hline $\begin{array}{l}\text { Participated in professional development } \\
\text { workshop(s) with a global focus }\end{array}$ & 189 & 55.10 \\
\hline Taken a globally focused course as a student & 166 & 48.54 \\
\hline $\begin{array}{l}\text { Participated in a short term study abroad } \\
\text { experience as a student ( } 1 \text { to } 3 \text { weeks) }\end{array}$ & 53 & 15.54 \\
\hline $\begin{array}{l}\text { Participated in a short term study abroad } \\
\text { experience as an adult ( } 1 \text { to } 3 \text { weeks) }\end{array}$ & 53 & 15.54 \\
\hline $\begin{array}{l}\text { Participated in a long term study abroad } \\
\text { experience as a student (more than } 3 \text { weeks) }\end{array}$ & 30 & 8.77 \\
\hline $\begin{array}{l}\text { Participated in a long term study abroad } \\
\text { experience as an adult (more than } 3 \text { weeks) }\end{array}$ & 19 & 5.54 \\
\hline $\begin{array}{l}\text { Lived outside the U.S. for a short duration for } \\
\text { personal reasons (less than } 1 \text { year) }\end{array}$ & 24 & 7.02 \\
\hline $\begin{array}{l}\text { Lived outside the U.S. for a short duration for } \\
\text { professional reasons (less than } 1 \text { year) }\end{array}$ & 21 & 6.12 \\
\hline $\begin{array}{l}\text { Lived outside the U.S. for a long duration for } \\
\text { personal reasons (more than } 1 \text { year) }\end{array}$ & 19 & 5.54 \\
\hline $\begin{array}{l}\text { Lived outside the U.S. for a long duration for } \\
\text { professional reasons (more than } 1 \text { years) }\end{array}$ & 16 & 4.71 \\
\hline
\end{tabular}




\section{Open-ended Responses}

\section{Strategies to Implement Global Citizenship Education.}

In order to capture a fuller picture of respondents’ experiences with global citizenship education and its integration with their programming, and to address research question \#4, the following open-ended questions were posed, "What barriers have you experienced while implementing global citizenship education components in your programming?” and "Please list up to five program strategies you have used to implement global citizenship education in your programming.” One hundred sixty-six individuals responded to the question about barriers. One hundred twenty-four individuals responded to the questions about program strategies. The respondents' answers were entered into an excel spreadsheet and sorted alphabetically. If the answer was left blank, or if the respondent answered with "not applicable,” those answers were removed from the spreadsheet. If, however, for the question regarding barriers, their answer was "none" that was interpreted to mean that they had experienced no barriers in their implementation of global citizenship education with their programming. After the aforementioned “not applicable” or blank responses were deleted, a total of 157 responses to the question about barriers and 105 responses for the question about strategies were included.

Although respondents' comments on the open-ended questions were quite diverse and reflected a variety of perspectives and experiences, some broad themes did emerge. Once these themes were identified, categories were created, and each respondent's answers were coded as to which category or categories best fit their response. For the 
question about strategies, the broad categories and recurring themes were determined to be:

- $\quad$ Food $(f=24)$

- $\quad$ Guest speakers $(f=21)$

- Hosting international youth $(f=20)$

- Incorporating Global Citizenship into other lessons $(f=20)$

- Curriculum $(f=14)$

- Technology $(f=7)$

- $\operatorname{Books}(f=7)$

- $\quad$ Media $(f=6)$

- Personal Travel $(f=5)$

- $\quad$ Youth exchanges $(f=5)$

- $\quad$ Agriculture/horticulture $(f=5)$

- $\quad$ Exposure to cultural items/artifacts $(f=2)$

Responses were given in all of the above categories, and additionally, some responses were given which didn’t readily fit into any of the broad themes (see appendix for all responses). Some categories received more numerous responses and were identified as the most popular strategies used by the extension employees responding to the survey. Of the 105 respondents, 24 indicated they had used food to incorporate a global perspective, 21 indicated they had used guest speakers, 20 indicated that they had incorporated global citizenship education components with their regular programming, 20 indicated that hosting international youth was a useful strategy, 14 indicated using curriculum to teach global citizenship, seven said they had used books with multicultural 
themes, seven said they had used technology, six said they had used media such as films, five said they had drawn upon their personal travel experiences, five indicated the use of youth cultural exchanges, five said they had taught global concepts through agricultural/horticulture, and two suggested exposing youth to cultural items or artifacts.

\section{Barriers Implementing Global Citizenship Education.}

For the question about the barriers experienced while implementing global citizenship education components in programming, the following broad themes were identified:

- $\quad$ Attitude/mindset $(f=41)$

- $\quad$ Time $(f=24)$

- Global citizenship education is a non-priority $(f=20)$

- Lack of resources $(f=20)$

- Lack of curriculum $(f=17)$

- Teaching this topic not perceived as respondents' role $(f=15)$

- Lack of money $(f=15)$

- $\quad$ No barriers perceived $(f=13)$

- Lack of diversity $(f=10)$

- Lack of administrative support $(f=4)$

- Language barrier $(f=4)$

As was the case with the question about strategies, the responses to the question about what barriers respondents had encountered touched on many diverse issues, and numerous types of barriers were identified (see appendix ? for complete list of 
responses). Several broad themes were identified, and categories were created based on these themes. Some categories are closely related, such as “money” and "resources," but although money could be identified as a resource, not all resources are monetary, and respondents used both words, with some respondents listed both money and resources in their answer, so total responses were tabulated for each term separately.

Of the 157 respondents who identified barriers to global citizenship education, 41 indicated attitude/mindset, 24 indicated lack of time, 20 said they felt the topic to be a non-priority, 20 indicated lack of resources, 17 said there was lack of curriculum, 15 said lack of money, 15 indicated that they felt it was not their role to address this topic, 13 respondents indicated they had experienced no barriers when implementing global citizenship education, 10 indicated lack of diversity, four said there was lack of administrative support, and four cited a language barrier as one of the impediments to teaching global citizenship.

\section{Discriminate Analysis}

Discriminative analysis was used to evaluate factors that influence individuals’ perceptions, attitudes, and opinions about global citizenship education. Six global personal perception questions were averaged and used to predict how the individuals rated their responses to questions concerning perceptions, attitudes, and opinions of global citizenship (see Table 23). The composite scores used were perceptions about curriculum, perceptions about supervision, attitudes about what youth should learn about global citizenship, opinions about learning through personal study, and opinions about learning through professional study. 
A stepwise discriminant analysis was conducted on the data to determine the best discriminators of respondents' responses to global citizenship. The five composite scores were used as potential discriminating variables in the statistical procedure. The null hypothesis tested was there would be no impact by attributes between the group centroids on the discriminant scores. At an alpha level of $\leq .05$, the null hypothesis was rejected and the research hypothesis was accepted that the composite scores did have an impact on respondent's responses to the personal perception of global citizenship questions. Two composite scores, curriculum and supervisor, loaded on the discriminant function when analyzed by their structure coefficients. The group centroids for global citizen and nonglobal citizen were -.579 and -.473 respectively (see Table 24 ). The canonical discriminant function coefficients for each attribute were .752 and .430 respectively.

To determine the similarity between a single variable and a discriminant function, the structure coefficient was examined. The structure coefficients were .918 for curriculum and .720 for supervisor signifying that the function was carrying nearly the same information as the variable (Klecka, 1980).

The Wilks' lambda is a multivariate measure of the group differences over the discriminating variables (Klecka, 1980). Values of lambda which approach zero indicate high discrimination. The analysis resulted in a Wilks' lambda of .756 indicated that $76 \%$ of the variance was unexplained. The eigenvalue of .323 indicated that the discriminant function can explain only .323 times as much as not being explained.

The canonical correlation coefficient is used to examine the relationship between the sets of variables. A large coefficient indicates a strong relationship between the 
groups and the discriminant function (Klecka, 1980). The canonical correlation coefficient was .494 which indicated the discriminant function accounted for $24.7 \%$ of the variance which could be explained.

The classification analysis results found that $71.7 \%$ of the original group cases were correctly classified (see Table 23). Based on curriculum and supervisor, the researcher can predict with 71.7\% accuracy if Extension employees who work with youth will perceive themselves as global citizens.

Table 23

Classification Table

\begin{tabular}{|c|c|c|c|c|c|}
\hline \multirow[b]{3}{*}{ Global Citizen } & \multirow{3}{*}{$\begin{array}{r}\text { Total } \\
137\end{array}$} & \multicolumn{4}{|c|}{ Predicted Group Membership } \\
\hline & & \multicolumn{2}{|c|}{ Global Citizen } & \multicolumn{2}{|c|}{ Non-Global Citizen } \\
\hline & & 106 & 77.4 & 31 & 22.6 \\
\hline Non-Global Citizen & 202 & 65 & 32.2 & 137 & 67.8 \\
\hline
\end{tabular}

a. $71.7 \%$ of original grouped cases correctly classified. 


\section{CHAPTER V}

\section{Summary, Discussion, and Recommendations}

\section{Purpose and Objectives of the Study}

The purpose of this study is to explore the perceptions, attitudes, and opinions of Extension workers on the topic of global citizenship education, and the possible barriers and strategies for implementing the topic in programming. The information gathered will indicate the current thinking of those teaching in this area, and will offer possible directions for delivering global citizenship programming in the future. The following research questions were used to guide the inquiry:

The objectives of this study are reflected in the following research questions:

1. What are Extension employees’ perceptions about global citizenship education?

2. What are Extension employees' attitudes about what content students should learn about global citizenship education?

3. What are Extension employees’ opinions about how they learn about global citizenship education?

4. What are Extension employees' feelings about barriers and program strategies for implementing global citizenship education?

5. What are Extension employees' past international experiences, and how does that impact current attitudes?

6. What characteristics can be used to discriminate between individuals with strong beliefs about global citizenship and those individuals with lesser beliefs about global citizenship? 
Assessing where Extension employees are in their own journeys toward achieving global citizenship will shed light on the current status of the initiative to produce globally competent young leaders. Additionally, knowledge about what strategies and programs are currently being used successfully should provide a springboard from which to develop new programming and curricula in the future. Identifying barriers to global citizenship education, whether stemming from organizational focus or from individuals' attitudes or lack of experience may also provide insight to specific ways to resolve these and move effectively toward the goal of exposing all youth to a global perspective.

\section{Summary}

Seven hundred eighty-six individuals responded to the survey. Four hundred eighty-seven said that they work with youth programming, whereas 299 said that they did not. Of the respondents who said that they work with youth programming, a total of 71 males and 271 females responded with demographic information. The majority of the men indicated that they worked as county agents. Of the women who responded, 124 worked in program support, and a nearly equal number, 121 worked as county agents.

Respondents were asked to describe their race using the same categories that are used by the United States Census Bureau. The overwhelming majority of respondents, 325 individuals, identified as "White." There were zero respondents who identified with the categories “American Indian or Alaskan Native” or “Native Hawaiian or Other Pacific Islander,” three who identified as “Asian,” and four who chose the category “Other (please specify).” 
Respondents were asked to describe their ethnicity using the categories "Hispanic" or "Non-Hispanic," and to choose only one answer that best described them. Five respondents or $1.46 \%$ identified as Hispanic, while 338 individuals (98.54\%) identified as Non-Hispanic.

When compared with U.S. Census statistics for the four states in which respondents reside, there is less diversity represented amongst the Extension Employees than there is generally in those states. For instance, $19.8 \%$ of Virginians, $12.9 \%$ of Ohioans, 8.4\% Kentuckians, and 3.6\% of West Virginians identified as Black or African American, while only $4.5 \%$ of survey respondents did so. Similarly, 9.4\% of Virginians, $3.8 \%$ of Ohioans, $3.7 \%$ of Kentuckians, and $1.6 \%$ of West Virginians identified as Hispanic or Latino while 1.45\% of survey respondents did so (Quick Facts Virginia; Ohio; Kentucky; West Virginia; United States, 2018). One possible avenue for further research would be to survey Extension employees from states with racial and ethnic demographics that more closely reflect the national averages, and to see if they exhibit increased knowledge about and support for global education initiatives.

Respondents were asked to indicate in which of the states they were currently employed. Eighty-eight respondents worked in Kentucky. One hundred eighteen worked in Ohio. Fifty-seven worked in Virginia. Eighty-five respondents worked in West Virginia. Over half of respondents indicated that they hold a Master's degree and over a quarter hold Bachelor's degrees.

Respondents were asked to report their age using six categories. None were under 20, and the rest appeared to fall along a bell curve with $12.39 \%$ indicating they were 21 - 
30, 23.63\% indicating 31-40, 27.95\% indicating 41-50, 25.94\% indicating 51-60, and $10.09 \%$ indicating they were 61 and over.

There are many levels of experience represented, and therefore, the study results represent the opinions and feelings of those who have less experience but perhaps new and fresh perspectives, and also those who have worked with 4-H for many years and can offer knowledge about programming that they have known to be successful, or can offer feedback about initiatives that have proven less effective. The category into which the largest number of respondents fell $(\mathrm{f}=\mathrm{80})$ was for having worked from one to five years, with the next highest number of respondents $(f=58)$ falling into the category of having worked for 11-15 years. The two categories at the extreme ends had a nearly equal number of respondents, with 40 individuals indicating they had worked with Extension for less than one year, and 42 individuals indicating that they had been employed for more than 25 years.

A little over half of respondents indicated that they had been members of 4-H while growing up, while 151 (43.27\%) said they had not been members. While over half of respondents reported having been members of 4-H during their youth, a very small number 5 (2.54\%) indicated that they had participated in a trip outside of the country through 4-H.

Less than a quarter of respondents reported working in a primarily urban area, while over three quarters of respondents (78.13\%) indicated that they primarily work in rural areas. Demographic data shows that urban areas in the U.S. have more racial and ethnic diversity, so an avenue for further inquiry might be to explore whether 
international experiences and opportunities for global education are more valued and promoted by Extension employees who work in urban areas.

A majority of respondents agreed or strongly agreed that they understood the meaning of global citizenship. Similarly, a majority of respondents stated that they agreed or strongly agreed with the statement that they feel global citizenship is an important part of 4-H programming. Respondents had positive feelings about the value of hosting international youth in their homes, as well as hosting international youth at 4-H camps, with the majority of respondents stating that they agree or strongly agree with statements about the importance of such experiences.

Overall, employees’ personal perceptions about the importance of global citizenship suggested that most Extension employees agree that gaining a global perspective is important and that global citizenship educational initiatives may occur in a variety of settings.

When given the statement "My administration supports global citizenship,” a majority of respondents agreed or strongly disagreed (63.63\%). Slightly less agreed or strongly agreed with the statement that their state Extension service is globally engaged. While these numbers do reflect a majority of individuals agreeing with the statement overall, there is still room for improvement in terms of global engagement. The least amount of support, or at least perceived support, focused on employee perceptions of 4-H volunteers. In fact, only $17.77 \%$ of respondents agreed or strongly agreed that $4-\mathrm{H}$ volunteers think global citizenship is important. This suggests that some education may be needed to help volunteers embrace global citizenship activities or curriculum. 
Given the statement "My 4-H youth think global citizenship is important," only $25.71 \%$ agreed or strongly agreed. This could indicate that some youth truly do not value global citizenship, or it could reflect a lack of understanding on the part of youth regarding what encompasses global citizenship. When asked if they felt 4-H educators should focus on local issues, $54.13 \%$ of respondents disagreed or strongly disagreed. This suggests that employees value a focus that encompasses a more global perspective, and want the youth that they work with to learn lessons that span from their local situations to national and global contexts.

When asked if they felt they had curriculum to teach global citizenship to the youth they work with, over a third of respondents disagreed to some extent. This suggests that there is a huge gap in either Extension employee's access resources, or the existence of available curriculum that focuses on global citizenship or incorporates a global perspective. Even given the perception of the lack of curriculum, over one third of respondents agreed or strongly agreed (35.9\%) that they can incorporate a global perspective in most lessons. A large majority of respondents agreed or strongly agreed (74.71\%) with the statement that they can teach global citizenship without leaving the country. Also encouraging for the future of global citizenship programming were Extension employees' responses to the statement, "It is the role of all 4-H educators to teach global citizenship” with $48.29 \%$ either agreed or strongly agreed.

Respondents were given a list of concepts and topic areas and asked how strongly they agreed or disagreed that students should learn more about them. No respondents disagreed that students should learn more about agriculture and food and this category had the largest number of respondents agree or strongly agree (96.91\%) that this should 
be an area of focus. The category with the second highest amount of agreement after agriculture and food was diversity with $92.11 \%$ agreeing or strongly agreeing that diversity is a topic about which youth should learn. Only two topics received more than a modicum of responses in any of the disagree columns and those were national politics and international politics. While the majority of respondents did agree or strongly agree that these should be taught, some did not. For national politics, twenty one individuals disagreed to some extent that this a topic that youth should learn. For the question about international politics, thirty respondents disagreed in some regard that this is a topic that youth should learn about global citizenship.

Extension employees appear to learn about global citizenship through a variety of experiences and in different settings. In general, respondents felt that they learned through both personal and professional activities.

The top response for learning about global citizenship through personal activities was having friends from different countries with 64.64\% expressing some level of agreement. The next highest categories by percentage of respondents agreeing or strongly agreeing was reading books (54.65\%), taking vacations in other countries (41.06\%), and reading periodicals (37.09\%).

The only category in which a large number of respondents disagreed to any extent (56.32\%) was learning through participation in study abroad programs. As discussed in the literature review, this is not something that is widely accessible to Extension employees and may be considered a peak experience when it comes to global citizenship.

Respondents were asked to answer "yes” or "no" to a list of statements describing whether or not they have participated in specific types of international experiences. The 
highest number of respondents, 194 (56.73\%) said they had traveled internationally for personal reasons. This experience was closely followed by participation in professional development workshops with global focus, with 189 (55.10\%) respondents answering "yes” to this experience. When asked if they had taken a globally focused course as a student, 166 (48.54\%) said they had. Given the experience "Integrated global examples or case studies in my youth programming,” 148 (43.53\%) answered in the affirmative.

While around half of respondents reported having the above experiences, the other categories which involve short and long-term international experiences had far fewer respondents reporting participation. The same number of respondents, 53(15.54\%) reported having a short term study abroad experience as a student as did those who had a short term study abroad experience as an adult. Thirty individuals reported having a long-term study abroad experience as a student, while 19 (5.54\%) said they had had a long-term study abroad experience as an adult. Twenty-four (7.02\%) respondents said they had lived outside the U.S. for a short duration for personal reasons, and 21 (6.12\%) said they had lived outside the U.S. for a short duration for professional reason. While these international experiences were probably highly impactful for these individuals in terms of gaining a global perspective, it must be noted that very few members of the total study population had had these types of experiences.

\section{Discussion and Recommendations}

Upon examination of the data received from this survey, some interesting information emerges. Most respondents felt that they understood the concept of global citizenship, agreed that it should be an important part of the programming they deliver to 
youth, and that it is included in 4-H's mission mandate. Significantly fewer individuals felt that that they had access to the necessary curriculum to effectively teach this topic. Based upon these findings, the researcher makes the following recommendations:

- Develop and disseminate curriculum that addresses the goal of global citizenship education since over 35\% of respondents did not feel they had adequate curriculum on the topic.

- Train Extension employees in ways they can incorporate a global perspective into their existing lessons and programming, since over $17 \%$ felt they were not able to do this.

- Provide resources for Extension employees that facilitate the inclusion of a global perspective within other lessons and topic areas.

- Use "skill-a-thons" and other existing curricula which present global citizenship information and encourage a global perspective.

Ideally, as was discussed in the literature review, global citizenship is a topic which is complementary to a variety of different lessons and subject areas and can be incorporated seamlessly by employees who are equipped with the resources and desire to do so.

Most respondents agreed that hosting international youth in individuals' homes as well as at 4-H camps are valuable global citizenship experiences. Activities such as these allow American youth exposure to cultures other than their own and allow for the formation of friendships between international youth and American youth which may be ongoing throughout their lifetimes. Having a friend from another country was cited as one way in which people learn about and value cultures other than their own. This suggests that the exposure to individuals who are culturally different in the form of youth 
exchanges and inbound programs which host international youth at 4- $\mathrm{H}$ camps are vitally important. They offer youth the chance to make friends from other cultures, and through social media and other forms of communication, they are able to stay in touch with these friends long after the cultural exchange is over. Based on these findings, recommendations are:

- Encourage Extension employees host youth from other countries at camps since nearly all respondents agreed that this is a valuable global citizenship experience.

- Promote hosting opportunities for individual club members and encourage those youth to share experiences in formal presentations.

- When hosting international youth, provide the opportunity for them to share their culture through song, stories, food or other means.

- Reach out to community members who can offer exposure to non-dominant cultures.

- Connect youth with pen pals (traditional or electronic) from other countries. This provides an opportunity for intercultural communication and exposure to diversity, both of which were deemed to be areas about which youth should learn more, according to a large majority of Extension employees.

Most respondents felt that their administration supported global citizenship efforts, and most also agreed that their Extension service was globally engaged, but many respondents did not agree that their volunteers valued global citizenship, and some also did not feel that global citizenship was something that the youth they teach felt was important. Considering that most respondents felt it was their duty to teach global citizenship, and that it is important to do so, responses seemed to point to a disconnect 
between perceptions of programming need and perceptions of program support among volunteer and youth clients. Recommendations include:

- Train volunteers on the importance of global citizenship as a life skill in our increasingly globalized society.

- Encourage and assist youth to engage in cultural exchange trips and share their experiences with others in formal presentations at camps, clubs, school, or community events.

- Develop classes and curriculum for youth which expose them to global citizenship concepts in ways they enjoy and are able to embrace.

- Recruit volunteers who already exhibit a global perspective.

- Recruit volunteers from diverse backgrounds.

- Expose volunteers and youth to accessible cultural experiences such as local fairs and festivals since most respondents agreed that this is a way in which they learn about cultures other than their own.

- Survey youth to determine which aspects of global citizenship are most valued and use responses to shape curricula and programming to increase youth buy-in. One result which stood out was the number of respondents who felt strongly about the importance of agriculture and food as areas that youth should learn more about within the context of global citizenship. Because a large number of respondents live in rural areas, and the youth they serve may be from families who live on or nearby farms, focusing on global citizenship as it relates to agriculture and food could be an effective method to teach youth about different cultures through topics with which they are familiar. This idea harkens back to some of the first youth exchanges that were 
facilitated by Extension when students learned about farming and agrarian lifestyles in other cultures through the IFYE program. Possibilities include:

- Create "global villages" which provide youth an immersive experience in which to learn about food, artifacts, and traditions without the need to travel.

- Host a meal which features international foods and invite community members with diverse cultural backgrounds to participate.

- Incorporate food and dishes from other cultures into meals and encourage discussion and comparison.

- Take youth to eat at local ethnic restaurants.

- Teach cooking lessons which feature international foods and ingredients.

\section{Discussion of Qualitative Responses}

When asked to give open-ended responses which identified barriers to implementing global citizenship education components with their programming, many respondents provided answers which fell into broad themes. Answers which were categorized as dealing with "attitude/mindset" could be in reference to administration, volunteers, youth, community stakeholders or others, but expressed a feeling that was either anti-global education or failed to see the value in this type of programming. Closely tied to this category, and expressing a similar sentiment were the answers that fell into the category deeming global citizenship education to be a non-priority. One respondent said, "Due to the rural, isolated area in which I live, a lot of our youth have limited experience with diversity and have not had a lot of exposure to different cultures. Often, I think that, as a result, many students are closed minded.” Another common response was that 
respondents felt that providing global citizenship education was not their role. These responses are interesting when juxtaposed to responses given in the other portion of the survey in which a large majority of respondents agreed with statements about feeling global citizenship education is an important part of youth programming and is a part of the National 4-H mission mandate. Some respondents seemed more willing or able to infuse a global perspective into other curriculum or programming, while others perceived barriers to doing so. Based upon the above findings, the researcher makes the following recommendations:

- Create a guide for Extension employees which contains specific strategies and ideas for incorporating global citizenship education into other types of programming.

- Hold workshops for Extension employees which explain global citizenship education’s importance to youth programming and teach individuals from various disciplines ways to weave this topic into the content areas they typically teach.

- Perform additional research to determine the methods used by those individuals who reported that they can incorporate a global perspective into various types of lessons.

Other common barriers mentioned by respondents were lack of time, lack of money, lack of resources, and lack of curriculum. While these are problems which plague many organizations, they need not be insurmountable barriers when attempting to implement global citizenship education, and it seems that other survey respondents have found ways to overcome these obstacles. Some respondents appeared to take a holistic approach to teaching this topic, and said they incorporated a global perspective through 
activities such as tasting exotic foods or tying in global food supply or non-native plants during lessons about agriculture. Others mentioned introducing topics of cultures, traditions, diversity and tolerance into discussions with youth. Some individuals listed lack of curriculum as a barrier, while others cited specific curriculum such as WeConnect, Diversity the Source of our Strength, Skill-a-thons, various books which feature diversity, as well as partnering with Junior Achievement in their work teaching global citizenship. "Curriculum” was a popular response to the question about barriers but was the only broad category which was also prominent among the responses to the question asking for successful strategies. This points to the idea that lack of curriculum or access to curriculum can pose a barrier, but availability of quality curriculum is a significant factor in the success of implementing global citizenship education. Some respondents listed technology as a means of bringing a global viewpoint to local youth. Based upon these findings, the researcher makes these recommendations:

- Provide training for Extension employees on ways to incorporate global perspectives that do not require large amounts of money or other resources.

- Provide lists of available resources and global citizenship curricula of which Extension employees may not be aware.

- Create additional curricula which addresses this topic for youth of various ages.

- Create curricula which ties this topic to other content areas and which can be used to encourage youth to have a global citizenship mindset in relation to content areas such as nutrition and agriculture. 
- Provide a list of ways to use technology such as skype, google earth, and virtual reality in order to help local youth connect with people and places that can broaden their perspectives.

While many respondents reported perceived barriers to infusing global citizenship lessons and perspectives into their programming, other respondents were able to identify and relate techniques and strategies that have proven effective for them in attempting to do so. Several of these involve little or no expense and may be more readily accessible than some employees realize. One respondent said, Offering cooking camps that teach about different cuisine and different regions, discussing gardening options and designs that might be used in different regions of the world, offering and encouraging youth to participate in study abroad options and exchange programs, encouraging families to host international exchange programs.

While another suggested, "Sharing origins of plant names and native habitats, sharing overseas experiences with volunteers, teaching about new vegetable introductions originating from other countries.”

The most popular strategy listed was the use of food to learn about other cultures. Whether simply tasting a new food or cooking a recipe using unfamiliar ingredients, the topic of eating and food is something which is universal to all humans and offers a way to learn about the similarities and differences between cultures and their traditions surrounding food. Food can also offer a jumping-off point for other discussions about various topics such as agriculture, nutrition, poverty, history, weather, climate, etc. Another strategy identified by several respondents as one that they employ that can be 
adopted with little or no expense is simply incorporating global citizenship concepts into their existing lessons and programming. This is admittedly more feasible if the employee possesses the knowledge and mindset of a "global citizen" but is something which should be possible for every educator to do to some degree.

Another popular strategy draws upon the experiences of community members, other stakeholders, or youth themselves. The use of guest speakers to broaden the knowledge and perspectives of young people in their journey toward global competency was listed by many respondents as a valuable strategy and is also one which typically can be done at little to no cost. Individuals who have emigrated from other countries or who have lived abroad can offer insights into different cultures which may be immensely valuable to youth who don't have the opportunity to travel themselves. Youth who have participated in exchange programs bring back with them cultural knowledge and broadened perspectives, which they can share with their peers. Finally, international youth who are being hosted as part of an exchange program may be given the opportunity to share their culture and traditions, and in so doing expose local youth to diversity and a more global outlook. Hosting international youth in community members' homes was listed by many as a way to expose local youth to cultures other than their own. Additionally, some respondents said they had used cultural items or artifacts to allow youth a hands-on experience, while others had employed media such as films with global themes. Based upon the strategies listed by respondents, the researcher makes the following recommendations:

- Incorporate food into lessons and use the topic to introduce various concepts related to global citizenship. 
- Provide Extension employees with concrete examples of ways to introduce global citizenship concepts into other subject areas.

- Utilize guest speakers representing varying perspectives and experiences to spark interest in global citizenship.

- Host youth as part of cultural exchanges, and invite them to speak and participate at local camps and clubs.

- Provide Extension employees with a database of films, music and other media which are conducive to enhancing global citizenship education.

- Create collections of cultural items such as fabrics, art, utilitarian items etc. which can be used as a lending library for classes, clubs, and camps to provide hands-on experiences when discussing global topics.

The data received through this survey has been useful in determining how Extension employees feel about global citizenship, experiences which contribute to greater mastery of the topic, its importance in curriculum, and in the lives of the youth with whom they work. It also points toward some avenues for additional research.

- It would be interesting to conduct a similar survey in states where greater diversity exists among Extension employees to see if a global perspective is more valued or considered to be more easily integrated across programming and curricula.

- More than half of respondents reported learning about global citizenship through professional development workshops. More information about the types of workshops deemed valuable and topics covered could guide the creation of future learning opportunities for Extension employees. 
- Many respondents reported living outside the country for professional or personal reasons as experiences which enhanced their global citizenship. An opportunity for further investigation would be to examine duration and type of experience to determine which contribute most to specific global citizenship education competencies.

- Because many respondents agreed that they learn about global citizenship through reading books and periodicals, watching television shows, and listening to radio and podcasts, a survey that determines a list of specific media which contributes to global citizenship education may be a useful resource for Extension employees.

This is a topic which deserves more study and an area which will continue to grow in importance as Extension employees grapple with the work of preparing local youth to be knowledgeable and engaged global citizens. 


\section{REFERENCES}

4-H Pledge. (2018). Retrieved from What is 4-H: https://4-h.org/about/what-is-4-h/4-hpledge/

Arnold, M. E., Davis, J., \& Corliss, A. L. (2014). From 4-H international youth exchange to global citizen: common pathways of ten past program participants. Journal of Youth Development, 9(2). Retrieved from http://jyd.pitt.edu/ojs/jyd/article/view/62

Boone, H. N., \& Boone, D. A. (2012). Analyzing Likert data. Journal of Extension, 50(2). Retrieved from https://www.joe.org/joe/2012april/tt2.php

Connors, J. J. (2004). FFA Costa Rican travel seminar participants' international agriculture knowledge and perceptions. Journal of International Agricultural and Extension Education, 11(1), 71-79. Retrieved from https://www.aiaee.org/index.php/vol-111-spring-04/194-ffa-costa-rican-travelseminar-participants-international-agriculture-knowledge-and-perceptions

Crilley, R. (2015, January 10). Jet stream blasts BA plane across Atlantic in record time. Retrieved from The Telegraph: https://www.telegraph.co.uk/news/worldnews/northamerica/usa/11337617/Jetstream-blasts-BA-plane-across-Atlantic-in-record-time.html

Daniel, J. B., Duncan, D., Navarro, M., \& Fuhrman, N. (2014). Experiential learning for extension professionals: A cross-cultural immersion program. Journal of Extension, 52(3). Retrieved from https://joe.org/joe/2014june/a4.php

Dillman, D., Smyth, J., \& Christian, L. (2009). Internet, mail and mixed-mode surveys: The tailored design method (3rd ed.). New York: Wiley. 
Dulock, H. L. (1993). Research design: Descriptive research. Journal of Pediatric Oncology Nursing, 10(4), 154-157. https://doi.org/10.1177/104345429301000406

Etling, A., Reaman, K. K., \& El Sawi, G. (1993). Overcoming barriers to a global outlook in 4-H. Journal of Extension, 31(2). Retrieved from https://joe.org/joe/1993summer/intl2.php

Gillespie, D. R. (2006). Keeping teens involved through state 4-H exchanges. Journal of Extension, 44(4). Retrieved from https://joe.org/joe/2006august/tt3.php

Harder, A., Lamm, A., \& Vergott III, P. (2010). Explore your world: Professional development in an international context. Journal of Extension, 48(2). Retrieved from https://joe.org/joe/2010april/a3.php

Hurst, S. D., Roberts, G. T., \& Harder, A. (2015). Beliefs and attitudes of secondary agriculture teachers about global agriculture issues. Journal of Agricultural Education, 56(1). Retrieved from https://files.eric.ed.gov/fulltext/EJ1122823.pdf Ingram, P. D. (1999). Attitudes of extension professionals toward diversity education in 4-H programs. Journal of Extension, 37(1). Retrieved from https://joe.org/joe/1999february/a3.php

Klecka, W. R. (1980). Discriminant analysis: Quantitative applications in the social sciences. London: Sage Publications

Lawler, B. R. (2007, April). The age of globalization: Impact of information technology on global business strategies.

Lockett, L., Moore, L., \& Wingenbach, G. (2014). A global worldview among extension professionals: A case study of best practices for study abroad programs. Journal of Extension, 52(4). Retrieved from https://joe.org/joe/2014august/a3.php 
Ludwig, B. G. (1996). U.S. Extension Systems--Facing the challenge to internationalize. Journal of Extension, 34(2). Retrieved from https://joe.org/joe/1996april/rb3.php

Ludwig, B. G. (2002a). Global in our backyard. Journal of Extension, 40(2). Retrieved from https://joe.org/joe/2002april/comm1.php

Ludwig, B. G. (2002b). Progress report--Globalizing U.S. Extension Systems. Journal of Extension, 40(2). Retrieved from https://joe.org/joe/2002april/rb1.php

National 4-H Council. (2018). 4-H citizenship. Retrieved from 4-H Official site: https://4h.org/parents/citizenship/

National 4-H Council. (n.d.). 4-H history. Retrieved from 4-H official website: https://4h.org/about/history/

Quick Facts Virginia; Ohio; Kentucky; West Virginia; United States. (2018). Retrieved from United States Census Bureau: https://www.census.gov/quickfacts/fact/table/va,oh,ky,wv,US/PST045218)

Robinson, J. P., Shaver, P. R., \& Wrightsman, L. S. (1991). Criteria for scale selection and evaluation. In J. P. Robinson, P. R. Shaver, \& L. S. Wrightsman (Eds.). Measures of personality and social psychological attitudes (pp. 1-16) New York: Academic Press.

Radhakrishna, R. B., \& Ingram, P. D. (2005). Experiences of 4-H Japanese exchange program on participants: An evaluative study. Journal of Extension, 43(3). Retrieved from https://joe.org/joe/2005june/rb3.php

Sallee, J., \& Lancaster, S. (2013). "...and my world:" Perceptions of county educators and volunteers toward international 4-H programs. Journal of Youth Development, 8(1). Retrieved from https://jyd.pitt.edu/ojs/jyd/article/view/107 
Schillings, K., \& Fox, J. (2011). National 4-H citizenship mission mandate logic models. Retrieved from www.nifa.usda.gov: https://nifa.usda.gov/sites/default/files/asset/document/4H\%20Citizenship\%20National\%20Logic\%20Model\%20\%28December\%202011 \%29.pdf

Seal, S. D., Peterson, D. J., Iwata, C., Kobia, C., \& Reddy, R. (2017). Expanding global mindedness through a 4-H international village. Journal of Extension, 55(2). Retrieved from https://www.joe.org/joe/2017april/iw4.php

Selby, K. A., Peters, J. L., Sammons, D. J., Branson, F. F., \& Balschweld, M. A. (2005). Preparing extension educators for a global community. Journal of Extension, 43(4). Retrieved from https://joe.org/joe/2005august/rb1.php

Skuza, J. A., \& Russo, J. P. (2014). WeConnect: A global youth citizenship curriculum. University of Minnesota Extension.

Stedman, N. L. (2016). Teaching locally, engaging globally: creating a community of global thinking fellows. Gainesville: University of Florida.

Stevens, G., Smith, B., \& Downing, A. (2014). International study abroad experiences with agents and students: A case study in Belize. Journal of Extension, 52(1). Retrieved from https://joe.org/joe/2014february/a10.php

Treadwell, P., Lachapelle, P., \& Howe, R. (2013). Extension learning exchange: Lessons from Nicaragua. Journal of Extension, 51(5). Retrieved from https://joe.org/joe/2013october/iw6.php 
Tritz, J., Cowger, T., Bennett, M., Fleisher, R., Hovatter, D., McCormack, C., ... Wilcox, V. (2012). Explore the world with a global education curriculum. Journal of Youth Development, 7(4). Retrieved from http://jyd.pitt.edu/ojs/jyd/article/view/122

US Department of Education. (2012). Succeeding globally through international education and engagement. Retrieved from US Department of Education: https://www2.ed.gov/about/inits/ed/internationaled/international-strategy-201216.pdf

Zhai, L., \& Scheer, S. D. (2004). Global perspectives and attitudes toward cultural diversity among summer agriculture students at The Ohio State University. Journal of Agricultural Extension, 45(2), 39-51. Retrieved from https://www.researchgate.net/publication/276227008_Global_Perspective_And_A ttitudes_Toward_Cultural_Diversity_Among_Summer_Agriculture_Students_At_ The_Ohio_State_University 
APPENDIX A

Cover Letter 
February 4, 2019

John Doe

123 Main Street

Anytown, USA 12345

Dear Extension Employee,

As an Extension employee you may have witnessed the 4-H program's effect on

youth and volunteers from a personal viewpoint. 4-H faculty and staff have the ability to deliver educational content in a variety of camp, club, classroom, and afterschool settings. Cooperative Extension Services at land-grant universities are each working on different aspects of state and national program areas, which typically include aspects of programming related to global citizenship. Since global citizenship education within the framework of 4-H may look different in certain counties and states, it will be interesting to discover if Extension employees' perceptions, attitudes, and opinions can lead to a better understanding of global citizenship program delivery.

My name is Denis Scott and I am a graduate student at West Virginia University. I am working with my advisor, Dr. Harry Boone, to conduct a research study to determine how Extension employees learn about global citizenship and what they think youth should learn about this subject is shaped by their perceptions, attitudes, and opinions. The results of this study will be used to prepare a dissertation to partially fulfill the requirements for a Doctor of Philosophy degree in Human and Community Development.

Since we are seeking a wide range of viewpoints, we are surveying Extension employees from different states, regardless of differing titles of staff or faculty. The results will provide awareness about the delivery of global citizenship education in different states and how content may be shaped by employees' feelings and experiences. An outcome of this study may be understanding best practices for employee training regarding global citizenship. Additionally, the study may help uncover employees' feelings about which delivery methods are best for teaching and engaging youth in global citizenship. Please take a few moments and share your opinions and experiences with us.

Participation in this research study is completely voluntary and all information you provide will be held as confidential as possible. The survey should take about fifteen minutes to complete and your response to the survey is crucial to the success of our study. You may skip any question you are not comfortable answering and you can stop at any time. You will receive an email that includes a link to our survey which will direct you to a website called Qualtrics. Survey results will be reported in a summary format and individual responses will not be identifiable as the website uses completely anonymous results.

The Institutional Review Board (IRB) at West Virginia University has approved this study and acknowledgement of this research is on file. If you have any questions or concerns about completing the questionnaire or about being a part of this study, you may contact me at Denis.Scott@mail.wvu.edu or my advisor Dr. Harry Boone at Harry.Boone@mail.wvu.edu or call 304-293-5451. Please submit your completed 
questionnaire before February 9th, 2019. Thank you in advance for your participation in this study. We sincerely appreciate your participation.

Sincerely,

Denis M. Scott

Harry N. Boone

Graduate Student

Professor 
APPENDIX B

First Follow-Up 


\section{First Follow-up: February 11, 2019}

On February 4, 2019, I invited you to participate in a research study on "Understanding Global Citizenship: Attitudes, Perceptions and Opinions." You are receiving a follow up email since Qualtrics indicated you did not complete the survey. Please take 15 minutes and provide your responses to the survey questions. Your opinions are vital to the success of the study. The original cover letter fully explaining the research study has been pasted below. Thank you again for your time and assistance.

\section{Follow this link to the Survey:}

$\$\{1: / /$ SurveyLink?d=Take the Survey $\}$

Or copy and paste the URL below into your internet browser:

\$ $\{1: / /$ SurveyURL $\}$

Follow the link to opt out of future emails:

$\$\{1: / / O p t O u t L i n k ? d=C l i c k$ here to unsubscribe $\}$

\section{Dear Extension Employee:}

As an Extension employee you may have witnessed the 4-H program's effect on youth and volunteers from a personal viewpoint. 4-H faculty and staff have the ability to deliver educational content in a variety of camp, club, classroom, and afterschool settings. Cooperative Extension Services at land-grant universities are each working on different aspects of state and national program areas, which typically include aspects of programming related to global citizenship. Since global citizenship education within the framework of 4-H may look different in certain counties and states, it will be interesting to discover if Extension employees' perceptions, attitudes, and opinions can lead to a better understanding of global citizenship program delivery.

My name is Denis Scott and I am a graduate student at West Virginia University. I am working with my advisor, Dr. Harry Boone, to conduct a research study to determine how Extension employees learn about global citizenship and what they think youth should learn about this subject is shaped by their perceptions, attitudes, and opinions. The results of this study will be used to prepare a dissertation to partially fulfill the requirements for a Doctor of Philosophy degree in Human and Community Development.

Since we are seeking a wide range of viewpoints, we are surveying Extension employees from different states, regardless of differing titles of staff or faculty. The results will provide awareness about the delivery of global citizenship education in different states and how content may be shaped by employees' feelings and experiences. An outcome of this study may be understanding best practices for employee training regarding global citizenship. Additionally, the study may help uncover employees’ feelings about which 
delivery methods are best for teaching and engaging youth in global citizenship. Please take a few moments and share your opinions and experiences with us.

Participation in this research study is completely voluntary and all information you provide will be held as confidential as possible. The survey should take about fifteen minutes to complete and your response to the survey is crucial to the success of our study. You may skip any question you are not comfortable answering and you can stop at any time. You will receive an email that includes a link to our survey which will direct you to a website called Qualtrics. Survey results will be reported in a summary format and individual responses will not be identifiable as the website uses completely anonymous results.

The Institutional Review Board (IRB) at West Virginia University has approved this study and acknowledgement of this research is on file. If you have any questions or concerns about completing the questionnaire or about being a part of this study, you may contact me at Denis.Scott@mail.wvu.edu or my advisor Dr. Harry Boone at HNBoone@mail.wvu.edu or call 304-293-5451. Please submit your completed questionnaire before February 9, 2019. Thank you in advance for your participation in this study. We sincerely appreciate your participation. 
APPENDIX C

Second Follow-Up 


\section{Second Follow-up: February 15, 2019}

On February 4, 2019, I invited you to participate in a research study on "Understanding Global Citizenship: Attitudes, Perceptions and Opinions." You are receiving a follow-up email since Qualtrics indicated you did not complete the survey. Please take a few minutes and provide your responses to the survey. If you do not work directly with youth through Extension the survey is only one question to complete.

Your opinions are vital to the success of the study to help understand a wide variety of perspectives. The original cover letter fully explaining the research study has been pasted below. Thank you again for your valuable time and assistance.

\section{Follow this link to the Survey:}

$\$\{1: / /$ SurveyLink?d=Take the Survey $\}$

Or copy and paste the URL below into your internet browser:

$\$\{1: / /$ SurveyURL $\}$

Follow the link to opt out of future emails:

$\$\{1: / / O p t O u t L i n k ? d=C l i c k$ here to unsubscribe $\}$

Dear Extension Employee:

As an Extension employee you may have witnessed the 4-H program's effect on youth and volunteers from a personal viewpoint. 4-H faculty and staff have the ability to deliver educational content in a variety of camp, club, classroom, and afterschool settings. Cooperative Extension Services at land-grant universities are each working on different aspects of state and national program areas, which typically include aspects of programming related to global citizenship. Since global citizenship education within the framework of 4-H may look different in certain counties and states, it will be interesting to discover if Extension employees' perceptions, attitudes, and opinions can lead to a better understanding of global citizenship program delivery.

My name is Denis Scott and I am a graduate student at West Virginia University. I am working with my advisor, Dr. Harry Boone, to conduct a research study to determine how Extension employees learn about global citizenship and what they think youth should learn about this subject is shaped by their perceptions, attitudes, and opinions. The results of this study will be used to prepare a dissertation to partially fulfill the requirements for a Doctor of Philosophy degree in Human and Community Development.

Since we are seeking a wide range of viewpoints, we are surveying Extension employees from different states, regardless of differing titles of staff or faculty. The results will provide awareness about the delivery of global citizenship education in different states and how content may be shaped by employees' feelings and experiences. An outcome of this study may be understanding best practices for employee training regarding global 
citizenship. Additionally, the study may help uncover employees' feelings about which delivery methods are best for teaching and engaging youth in global citizenship. Please take a few moments and share your opinions and experiences with us.

Participation in this research study is completely voluntary and all information you provide will be held as confidential as possible. The survey should take about fifteen minutes to complete and your response to the survey is crucial to the success of our study. You may skip any question you are not comfortable answering and you can stop at any time. You will receive an email that includes a link to our survey which will direct you to a website called Qualtrics. Survey results will be reported in a summary format and individual responses will not be identifiable as the website uses completely anonymous results.

The Institutional Review Board (IRB) at West Virginia University has approved this study and acknowledgement of this research is on file. If you have any questions or concerns about completing the questionnaire or about being a part of this study, you may contact me at Denis.Scott@mail.wvu.edu or my advisor Dr. Harry Boone at HNBoone@mail.wvu.edu or call 304-293-5451. Please submit your completed questionnaire before February 9, 2019. Thank you in advance for your participation in this study. We sincerely appreciate your participation. 
APPENDIX D

Third Follow-Up 


\section{Third Follow-up: February 20, 2019}

On February 4, 2019, I invited you to participate in a research study on "Understanding Global Citizenship: Attitudes, Perceptions and Opinions." You are receiving a follow-up email since Qualtrics indicated you did not complete the survey. Please take a few minutes and provide your responses to the survey. If you do not work directly with youth through Extension the survey is only one question to complete.

Your opinions are vital to the success of the study to help understand a wide variety of perspectives. The original cover letter fully explaining the research study has been pasted below. Thank you again for your valuable time. I really appreciate your assistance!

\section{Follow this link to the Survey:}

$\$\{1: / /$ SurveyLink?d=Take the Survey $\}$

Or copy and paste the URL below into your internet browser:

$\$\{1: / /$ SurveyURL $\}$

Follow the link to opt out of future emails:

$\$\{1: / / O p t O u t L i n k ? d=C l i c k$ here to unsubscribe $\}$

Dear Extension Employee:

As an Extension employee you may have witnessed the 4-H program's effect on youth and volunteers from a personal viewpoint. 4-H faculty and staff have the ability to deliver educational content in a variety of camp, club, classroom, and afterschool settings. Cooperative Extension Services at land-grant universities are each working on different aspects of state and national program areas, which typically include aspects of programming related to global citizenship. Since global citizenship education within the framework of 4-H may look different in certain counties and states, it will be interesting to discover if Extension employees' perceptions, attitudes, and opinions can lead to a better understanding of global citizenship program delivery.

My name is Denis Scott and I am a graduate student at West Virginia University. I am working with my advisor, Dr. Harry Boone, to conduct a research study to determine how Extension employees learn about global citizenship and what they think youth should learn about this subject is shaped by their perceptions, attitudes, and opinions. The results of this study will be used to prepare a dissertation to partially fulfill the requirements for a Doctor of Philosophy degree in Human and Community Development.

Since we are seeking a wide range of viewpoints, we are surveying Extension employees from different states, regardless of differing titles of staff or faculty. The results will provide awareness about the delivery of global citizenship education in different states and how content may be shaped by employees' feelings and experiences. An outcome of this study may be understanding best practices for employee training regarding global 
citizenship. Additionally, the study may help uncover employees' feelings about which delivery methods are best for teaching and engaging youth in global citizenship. Please take a few moments and share your opinions and experiences with us.

Participation in this research study is completely voluntary and all information you provide will be held as confidential as possible. The survey should take about fifteen minutes to complete and your response to the survey is crucial to the success of our study. You may skip any question you are not comfortable answering and you can stop at any time. You will receive an email that includes a link to our survey which will direct you to a website called Qualtrics. Survey results will be reported in a summary format and individual responses will not be identifiable as the website uses completely anonymous results.

The Institutional Review Board (IRB) at West Virginia University has approved this study and acknowledgement of this research is on file. If you have any questions or concerns about completing the questionnaire or about being a part of this study, you may contact me at Denis.Scott@mail.wvu.edu or my advisor Dr. Harry Boone at HNBoone@mail.wvu.edu or call 304-293-5451. Please submit your completed questionnaire before February 9, 2019. Thank you in advance for your participation in this study. We sincerely appreciate your participation. 
APPENDIX E

Fourth Follow-Up 


\section{Fourth Follow-up: February 25, 2019}

On February 4, 2019, I invited you to participate in a research study on "Understanding Global Citizenship: Attitudes, Perceptions, and Opinions." You are receiving a final follow-up email since Qualtrics indicated you did not complete the survey. Please take a few minutes and provide your responses to the survey before February 28. If you do not work directly with youth through Extension the survey is only one question to complete.

It is not too late to share your opinions. Your responses are vital to the success of the study to help understand a wide variety of perspectives. The original cover letter fully explaining the research study has been pasted below. Thank you again for your valuable time and assistance!

Follow this link to the Survey:

$\$\{1: / /$ SurveyLink?d=Take the Survey\}

Or copy and paste the URL below into your internet browser:

$\$\{1: / /$ SurveyURL $\}$

Follow the link to opt out of future emails:

$\$\{1: / / O p t O u t L i n k ? d=C l i c k$ here to unsubscribe $\}$

Dear Extension Employee:

As an Extension employee you may have witnessed the 4-H program's effect on youth and volunteers from a personal viewpoint. 4- $\mathrm{H}$ faculty and staff have the ability to deliver educational content in a variety of camp, club, classroom, and afterschool settings. Cooperative Extension Services at land-grant universities are each working on different aspects of state and national program areas, which typically include aspects of programming related to global citizenship. Since global citizenship education within the framework of 4-H may look different in certain counties and states, it will be interesting to discover if Extension employees' perceptions, attitudes, and opinions can lead to a better understanding of global citizenship program delivery.

My name is Denis Scott and I am a graduate student at West Virginia University. I am working with my advisor, Dr. Harry Boone, to conduct a research study to determine how Extension employees learn about global citizenship and what they think youth should learn about this subject is shaped by their perceptions, attitudes, and opinions. The results of this study will be used to prepare a dissertation to partially fulfill the requirements for a Doctor of Philosophy degree in Human and Community Development.

Since we are seeking a wide range of viewpoints, we are surveying Extension employees from different states, regardless of differing titles of staff or faculty. The results will provide awareness about the delivery of global citizenship education in different states and how content may be shaped by employees' feelings and experiences. An outcome of 
this study may be understanding best practices for employee training regarding global citizenship. Additionally, the study may help uncover employees' feelings about which delivery methods are best for teaching and engaging youth in global citizenship. Please take a few moments and share your opinions and experiences with us.

Participation in this research study is completely voluntary and all information you provide will be held as confidential as possible. The survey should take about fifteen minutes to complete and your response to the survey is crucial to the success of our study. You may skip any question you are not comfortable answering and you can stop at any time. You will receive an email that includes a link to our survey which will direct you to a website called Qualtrics. Survey results will be reported in a summary format and individual responses will not be identifiable as the website uses completely anonymous results.

The Institutional Review Board (IRB) at West Virginia University has approved this study and acknowledgement of this research is on file. If you have any questions or concerns about completing the questionnaire or about being a part of this study, you may contact me at Denis.Scott@mail.wvu.edu or my advisor Dr. Harry Boone at HNBoone@mail.wvu.edu or call 304-293-5451. Please submit your completed questionnaire before February 28, 2019. Thank you in advance for your participation in this study. We sincerely appreciate your participation. 
APPENDIX F

Instrument 
Default Question Block

Understanding Global Citizenship:

Extension Employees' Perceptions, Attitudes, and Opinions

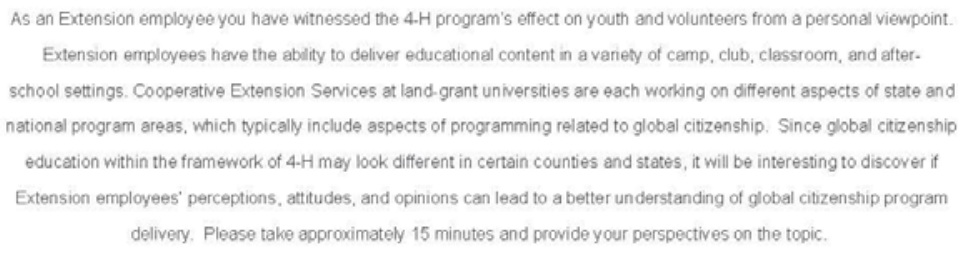

Do you work with youth programming?

Yes

No

\section{Extension Employees' Perceptions about Global Citizenship}

Instructions: Using the following Likert scale, indicate your level of agreement with each of the following statements. Indicate your opinion by choosing one response for each statement. The responses range from a "strongly disagree" to a "strongly agree."

\begin{tabular}{|c|c|c|c|c|c|c|}
\hline & $\begin{array}{l}\text { Strongly } \\
\text { disagree }\end{array}$ & Disagree & $\begin{array}{c}\text { Slightly } \\
\text { disagree }\end{array}$ & $\begin{array}{l}\text { Slightly } \\
\text { agree }\end{array}$ & Agree & $\begin{array}{l}\text { Strongly } \\
\text { agree }\end{array}$ \\
\hline $\begin{array}{l}\text { I understand the meaning of } \\
\text { global citizenship }\end{array}$ & 0 & 0 & 0 & 0 & 0 & 0 \\
\hline $\begin{array}{l}\text { I feel global citizenship is an } \\
\text { important part of 4-H programming }\end{array}$ & 0 & 0 & 0 & 0 & 0 & 0 \\
\hline $\begin{array}{l}\text { Global citizenship is part of the } \\
\text { national 4-H mission mandates }\end{array}$ & 0 & 0 & 0 & 0 & 0 & 0 \\
\hline $\begin{array}{l}\text { My administration supports global } \\
\text { citizenship }\end{array}$ & 0 & 0 & 0 & 0 & 0 & 0 \\
\hline $\begin{array}{l}\text { I have curriculum to teach global } \\
\text { citizenship }\end{array}$ & 0 & 0 & 0 & 0 & 0 & 0 \\
\hline $\begin{array}{l}\text { I can incorporate a global } \\
\text { perspective in most lessons }\end{array}$ & 0 & 0 & 0 & 0 & 0 & 0 \\
\hline $\begin{array}{l}\text { I can teach global citizenship } \\
\text { without leaving the country }\end{array}$ & 0 & 0 & 0 & 0 & 0 & 0 \\
\hline $\begin{array}{l}\text { My state Extension service is } \\
\text { globally engaged }\end{array}$ & 0 & 0 & 0 & 0 & 0 & 0 \\
\hline $\begin{array}{l}\text { My 4-H volunteers think global } \\
\text { citizenship is important }\end{array}$ & 0 & 0 & 0 & 0 & 0 & 0 \\
\hline $\begin{array}{l}\text { My 4-H youth think global } \\
\text { citizenship is important }\end{array}$ & 0 & 0 & 0 & 0 & 0 & 0 \\
\hline $\begin{array}{l}\text { 4-H educators should focus on } \\
\text { local issues }\end{array}$ & 0 & 0 & 0 & 0 & 0 & 0 \\
\hline $\begin{array}{l}\text { I equate global citizenship with } \\
\text { study abroad trips }\end{array}$ & 0 & 0 & 0 & 0 & 0 & 0 \\
\hline $\begin{array}{l}\text { Hosting international youth in } \\
\text { one's home is a valuable global } \\
\text { citizenship experience }\end{array}$ & 0 & 0 & 0 & 0 & 0 & 0 \\
\hline $\begin{array}{l}\text { Hosting international youth at 4-H } \\
\text { camps is a valuable global } \\
\text { citizenship experience }\end{array}$ & 0 & 0 & 0 & 0 & 0 & 0 \\
\hline
\end{tabular}


Qualtrics Survey Software

Strongly
disagree Disagree dishtly $\begin{gathered}\text { Slightly } \\ \text { disagree }\end{gathered}$ agree Agree $\begin{gathered}\text { Strongly } \\ \text { agree । }\end{gathered}$

It is the role of all 4-H educators to teach global citizenship

$\begin{array}{lllllll}0 & 0 & 0 & 0 & 0 & 0\end{array}$

Extension Employee Attitudes About

What Youth Should Learn Related to Global Citizenship

Instructions: Using the following Likert scale, indicate your level of agreement with each of the following statements. Incicate your opinion by choosing one response for each statement. The responses range from a "strongly disagree" to a "strongly agree."

Students should learn more about...

\begin{tabular}{|c|c|c|c|c|c|c|}
\hline & $\begin{array}{l}\text { Strongly } \\
\text { disagree }\end{array}$ & Disagree & $\begin{array}{l}\text { Slightly } \\
\text { disagree }\end{array}$ & $\begin{array}{l}\text { Slightly } \\
\text { agree }\end{array}$ & Agree & $\begin{array}{c}\text { Strongly } \\
\text { agree }\end{array}$ \\
\hline Their own heritages & 0 & 0 & 0 & 0 & 0 & 0 \\
\hline Global issues & 0 & 0 & 0 & 0 & 0 & 0 \\
\hline Cultural issues & 0 & 0 & 0 & 0 & 0 & 0 \\
\hline Agriculture and food & 0 & 0 & 0 & 0 & 0 & 0 \\
\hline Arts and history & 0 & 0 & 0 & 0 & 0 & 0 \\
\hline $\begin{array}{l}\text { Communication, media, and } \\
\text { technology }\end{array}$ & 0 & 0 & 0 & 0 & 0 & 0 \\
\hline Geography & 0 & 0 & 0 & 0 & 0 & 0 \\
\hline National politics & 0 & 0 & 0 & 0 & 0 & 0 \\
\hline International politics & 0 & 0 & 0 & 0 & 0 & 0 \\
\hline Intercultural communication & 0 & 0 & 0 & 0 & 0 & 0 \\
\hline Diversity & 0 & 0 & 0 & 0 & 0 & 0 \\
\hline
\end{tabular}

Extension Employee Opinions About How They Learn About Global Citizenship

Instructions: Using the following Likert scale, indicate your level of agreement with each of the following statements. Indicate your opinion by choosing one response for each statement. The responses range from a "strongly disagree" to a "strongly agree."

I learned about global citizenship by...

\begin{tabular}{|c|c|c|c|c|c|c|}
\hline & $\begin{array}{l}\text { Strongly } \\
\text { disagree }\end{array}$ & Disagree & $\begin{array}{l}\text { Slightly } \\
\text { disagree }\end{array}$ & $\begin{array}{l}\text { Slightly } \\
\text { agree }\end{array}$ & Agree & $\begin{array}{l}\text { Strongly } \\
\text { agree }\end{array}$ \\
\hline $\begin{array}{l}\text { Watching selected television } \\
\text { programs }\end{array}$ & 0 & 0 & 0 & 0 & 0 & 0 \\
\hline Professional development & 0 & 0 & 0 & 0 & 0 & 0 \\
\hline My college classes & 0 & 0 & 0 & 0 & 0 & 0 \\
\hline $\begin{array}{l}\text { Attending community events such } \\
\text { as cultural festivals or shows }\end{array}$ & 0 & 0 & 0 & 0 & $\mathrm{O}$ & 0 \\
\hline $\begin{array}{l}\text { Participating in study abroad } \\
\text { programs }\end{array}$ & 0 & 0 & 0 & 0 & 0 & 0 \\
\hline Taking vacations in other countries & 0 & 0 & 0 & 0 & 0 & 0 \\
\hline Listening to selected radio programs & 0 & 0 & 0 & 0 & 0 & 0 \\
\hline Engaging in social media & 0 & 0 & 0 & 0 & 0 & 0 \\
\hline Listening to podcasts & 0 & 0 & 0 & 0 & 0 & 0 \\
\hline
\end{tabular}




\section{Qualtrics Survey Software}

$\begin{array}{lcccccc} & \begin{array}{c}\text { Strongly } \\ \text { disagree }\end{array} & \text { Disagree } & \begin{array}{c}\text { Slightly } \\ \text { disagree }\end{array} & \begin{array}{c}\text { Slightly } \\ \text { agree }\end{array} & \text { Agree } & \begin{array}{c}\text { Strongly } \\ \text { agree }\end{array} \\ \text { Reading periodicals } & 0 & 0 & 0 & 0 & 0 & 0 \\ \text { Reading books } & 0 & 0 & 0 & 0 & 0 & 0 \\ \begin{array}{l}\text { Having friends from different } \\ \text { countries }\end{array} & 0 & 0 & 0 & 0 & 0 & 0\end{array}$

Past International Experiences of Extension Employees

Instructions: Using the following Likert scale, indicate your level of agreement with each of the following statements. Indicate your opinion by choosing one response for each statement. The responses range from a "strongly disagree" to a "strongly agree."

I have...

$\begin{aligned} & \text { Integrated global examples or case studies in my } \\ & \text { youth programming }\end{aligned}$
$\begin{aligned} & \text { Traveled internationally for personal reasons (i.e. } \\ & \text { vacation, etc.) }\end{aligned}$

Demographics

What is your gender?

Male

Female

What is your race?

American Indian or Alaska Native

Asian

Black or African American

Native Hawaiian or Other Pacific Islander

White

Other (Please specify) 
What is your ethnicity (check only one)?

Hispanic

Non-Hispanic

In which state are you currently employed?

Kentucky

Ohio

Virginia

West Virginia

What is your primary responsibility?

Program support

County Agent

Area or District Agent

State Specialist

Administration

Please indicate the highest degree that you have attained.

Less than a high school diploma

High school diploma or equivalent

Bachelor's degree

Master's degree

Doctoral degree

What is your age?

Under 20

$21-30$

$31-40$

$41-50$

$51-60$

61 and over

How many years of experience working with $4-\mathrm{H}$ do you have?

Less than one year

$1-5$ years

$6-10$ years

$11-15$ years

16-20 years

$21-25$ years

Over 25 years

How many years have you been working in your current position?

Less than one year

$1-5$ years

6-10 years

11-15 years 
16-20 years

$21-25$ years

Over 25 years

Were you a 4-H member as a youth?

Yes

No

As a youth, did you participate in a 4-H affiliated trip outside of the country (international program, exchange, States' 4 H Intemational, IFYE, etc.)?

Yes

No

Do you work in a primarily urban or rural area?

Urban

Rural

Do you work primarily in a county that is designated as Appalachia by the Appalachian Regional Commission?

Yes

No

Not sure

What is your primary focus area?

Agriculture and Natural Resources

Community and Economic Development

Families and Health

4- $\mathrm{H}$ and Youth Development

Other

If you indicated "other," please specify.

What barriers have you experienced while implementing global citizenship education components in your programming?

Please list up to five program strategies you have used to implement global citizenship education in your programming?

I would like to thank you for taking the time to respond to my survey. Thank you. 
APPENDIX G

Responses to Open-ended Questions 


\section{Open-ended Responses}

The following responses were taken from the survey verbatim and no corrections for spelling or grammar were made.

\section{Q22 - What barriers have you experienced while implementing global citizenship education components in your programming?}

we don't currently implement global citizenship education in our programming.

using accurate current research based information

transportation for students to programs, parental support

trained volunteers to teach the program; youth receptive to global programming;

curriculum to use; community resources to bring in

time and information

time

this is the first I have heard about global citizenship education we are US citizens and programs are open to the public including non-citizens we include history as part of the programs and this can get into some global education stuff and can show the differences that US citizenship brings to us as compared to other countries. Americans have it made when comparing to the rest of the world.

there are no/little international residents so it is not of interest

the meaning of citizenship

not many resources are offered in other languages

none

none

none

none

none

none

na 
$\mathrm{n} / \mathrm{a}$

money and time

money

materials and supplies

limited freedom to explore topic in public schools where I teach nutrition. Suspect a lot of parents have biases against 'foreigners' and including them here.

language translation

lack of knowledge and understanding on World Geography and US History and more

knowledge and resources

it isn't something I incorporate in programming

interest from schools

implementation

grant funded program with set curriculum

funding

expense, lack of interest, lack of volunteers interested, lack of time/space, youth aren't aware of local issues so covering something global before they understand local is a stretch

easy to use, ready to go curriculum to teach it

closed mindedness

clients thinking the topic is not important

assumptions

Youth will 'tease' or make 'gross' comments about other culture's food choices. Youth not being willing to try new foods.

Youth struggle to see connections with what we are learning and what is happening around the world. They are primarily concerned with what is happening in their own community. They see the problems happening here in the community like the drug use and lack of opportunities and 
We only speak of it in general terms when discussing new and usual vegetables or fruits

Tradition, cost,

Too many subjects to cover to focus on areas outside county leadership's

recommendations. No personal burning desire to travel or provide this content.

Time, staff, resources

Time to plan for global integration into my lessons

Time and resource management

Time and funding and local needs for a large traditional program. I can't get ahead of myself to implement new programs and ideas.

Time and families making the commitment

Time - that is, "how can I fit in one more program"?

Time - I cannot add another stand alone program.

Time

Time

Three year rule for traveling out of the country is a barrier.

The reception of the subject matter from others. They do not always understand the importance of global citizenship education.

The people who are attracted to our volunteer and public education programming are not very diverse. It is hard to reach the full demographic or our jurisdiction here we have to take programming to them.

The majority of our county are very conservative and not open minded to learning about other cultures. If the lesson doesn't revolve around small town life or coal, it's very difficult to get people to care.

The cost of doing an experience. Youth want to learn but cannot afford to travel. Many have never traveled out of state.

That is not an important issue inside my own county, even though it is rich in cultural and ethnic diversity. There is not enough awareness, that we, in this day and age function and live in a global economy as producers, consumers and citizens. Other youth orientated organizations such as Junior Achievement is ahead of 4- $\mathrm{H}$ on 
implementing global citizenship education that is far reaching, expansive, and across many places of youth education. We need to catch up and surpass.

Sticking to strict programming

Starting point of youth and adults who 'other' other societies/cultures too much (which also points to the importance of this work). Funding. Balance of local stakeholders (State and County Administrators) who think 4-H should only be focused on local issues.

Sometimes it is not relevant when youth have little understanding of things happening at a local level or they are not safe and secure in their own lives, so learning the hardships of others in a global setting is not interesting to them.

Some $4 \mathrm{H}$ programs do not want to work with the urban areas.

Resources and materials that are universally adoptable to a variety of audiences.

Resources

Resistance of learning because of lack of diversity exposure of adults and youth in the county

Regional bias against learning about people from different cultures, lack of clear explanation of how this "fits" with 4-H programming, administration that doesn't seem to value multi-cultural competency

Quality curricula

Program resources

People not realizing we all have global connections.Skill

People in my region don't think this is important.

People are more concerned about county/state issues and it is often hard to find time to complete specific programming for global citizenship. However, the general topic of citizenship is always incorporated in my programs, especially with older youth

Participants lack of knowledge, I don't really consider this a barrier just an obstacle.

Our work with children mainly focuses on gardening. We do not do anything on global citizenship education

Our rural youth have no concept of simply going to the State Capitol or to Washington DC. Those big cities are a culture shock for them (and most of their parents). To conceptualize something on a global scale is equally challenging. 
Not understanding our curriculum.

Not immediately relevant to rural clients who are only tied in to local governments, local companies, and local businesses at best. Deal slightly more with global corporations. Don't like them. Also don't like/trust federal/international political bodies. Less control, less relevance, crazy policies, limited exposure or perceived positive benefits only restrictions

Not having experienced it myself

None.

None

None

None

None

None

None

New agent training, time restraints, availability and awareness to curriculum and resources

NA

N/A

N/A

N/A

N/A

N/A

N/A

My own knowledge regarding global citizenship topics - I teach nutrition lessons

Money, can't afford trips or anything like that. I also can't take off work to enjoy 3-6 weeks in another country. Farmers don't move so they don't really have an interest

Money to fund programs. Motivating agents to promote and encourage international programs as well as get involved. 
Many youth have not had broad enough life experiences to appreciate the need to learn about other cultures.

Many people in our community don't even travel much within our state let alone country and they really don't seem to have any interest in anything but local information.

Local volunteers are not particularly interested in global programming as well as about $70 \%$ of the 4-Hers. They are from an isolated small town and aren't really interested in exploring the world.

Local mindsets.

Living in an area with no racial or ethnic diversity makes integrating issues of global citizenship difficult because most youth have no frame of reference \&/or cannot personally relate to the info making it out of site / out of mind. Many youth have heard their entire life Appalachia is low SES which seems to support an "us against them" mentality or encourage plans to leave ASAP. There is little connection and/or empathy to how

Living in Eastern Kentucky in a very disadvantaged area, most people I work with are of limited resources and rely on government benefits. Most have not traveled outside of Kentucky, if out of this part of Kentucky so they have a hard time seeing a global perspective. They have so many hardships locally that they can't expand their thoughts to those in other areas.

Little time available, competing topics

Limited exposure to other cultures by participants

Limited access to travel or meeting other nationalities

Length of event.

Lack of resources for activities to promote global education.

Lack of resources and opportunities.

Lack of racial diversity within the county. 98.7\% white population.

Lack of interest; lack of funds if a youth or adult volunteer was interested in an international exchange. Decreasing population, high unemployment, and 25\% poverty rate make fundraising extremely difficult.

Lack of interest in global citizenship and programming, unless it involves international travel

Lack of interest 


\section{Lack of exposure}

Just not taking the time to be purposeful about integrating global citizenship programming

It needs to be more of an emphasis in community club programming but, as with anything, there is never enough time or personnel at the county level.

It just isn't part of a lot of the curriculum

It is not a priority focus area for our programming and does not take priority for our outcomes. It is not listed as one of our impact areas. Local programs do not consider global citizenship on their radar of essential issues.

It is easier to focus on local/state initiatives in youth programming for many reasons: 1) lack of experience on the part of Extension personnel, 4-H/youth group leaders, and volunteers that complete the educational activities. Time vs reward, finding time to expand beyond the required programs that dominate delivery content. Sheltered (my word, but may not be the best word) or uninformed communities.

Interest in our county as a whole.

Inherent bias or a feeling of already knowing everything by the target population that you are teaching. Mostly from an adult perspective, not youth.

In previous position global programming received only lukewarm support from Extension administration, or at times outright hostility.

In nutrition we do not purpose ourselves to teach global citizenship but elements of the same show up in themes (taking care of one's body, being an encourager of others, ) but the biggest barrier to understanding of the outside world is many of our youth have never traveled outside the county, or the state, much less overseas.

I work in a county which is $98 \%$ white. We do not encounter substantial numbers of clients with different cultural backgrounds. I work mostly with populations within a poverty culture and food insecurity. In my programs we do explore diverse cultural diets.

I usually only teach youth in nutrition programming or work with youth on clothing projects.

I teach a very focused sewing program and have no extra time to teach these concepts. It is integrated into the clothing design part of 1 class I teach.

I lack the curriculum to implement into existing programs.

I haven't had the experience of leading a lesson or implementing any programming 
I have personal and professional global experience. But other than the visitation of the exchange students I have not been give any tools, resources or training on global citizenship. What are the priorities, how should we be integrating it into our programs. The truth is that other than my own resources, unless something is provided that makes sense, I probably won't do it. And most importantly, I think this is very important, relevant and I want to work with it. But the environment for success must be created.Right now, that doesn't exist.

I have not tried to implement

I have not been employed long enough to know yet

I have never implemented global citizenship

I don't implement global citizenship in my programming as our focus is nutrition education .

I do not work for 4H, don't know why I'm taking this survey, and don't teach global citizenship.

I do not usually focus on global citizenship. I am not sure I have the information if I did include it.

I do not teach the youth, the Agents do that.

I do not implement a lot of programming yet. I am still trying to learn everything in this role.

I am still new and am learning the programs we are teaching.

I am not a 4-H Educator. Rather, I am a Program Assistant for EFNEP.

I am new to the county so I am still figuring out the counties dynamics and its personnel.

I am grant funded so I have specific criteria that i work under

Having materials in Spanish and knowing where local interpreters are located in the county I serve.

Having curricula that meets the KY Common Core Standards.

Have not implemented any, other than bringing up the diet in other countries.

Hard to find Host families for exchange programs because of the length of time. 
Global citizenship is not a priority identified by the community. It is hard to find time for global citizenship education with all other areas education already being implemented.

General lack of community knowledge.

Funding to support a youth-organized educational immersion trip overseas

Funding and resources are a challenge when wanting to do some bigger things (like actual international travel/exchange)

Funding

Fun hands on activities - I have used some, but tweaked them to use cryptology to make even more challenging and engaging

Food Insecurity

Finding STEM-related curriculum that would also enhance global citizenship to 10-11 year old students

Finances and lack of resources, lack of understanding of importance

Due to the rural, isolated area in which I live, a lot of our youth have limited experience with diversity and have not had a lot of exposure to different cultures. Often, I think that, as a result, many students are closed minded to key elements of global citizenship and are often critical of practices, traditions, foods and religions that differ from their own. For these students, their concept of identity is limited to community, state, and nation.

Don't understand what that is.

Difficulty integrating non-English speakers into programs AND lack of understanding among native English speakers about the need for "special” programming to meet nonEnglish speaking participants.

Determining where to begin with the youth in my VERY rural community...

Could not get kids involved.

Connectivity - lack of county-wide high-speed internet access

Communication barriers

Closeminded volunteers or parents.

Being an editor, I don't implement the global citizenship educational components. 
Being able to find sufficient time to incorporate it into lessons.

Available resources

Attitude of clientele

Administrative support

A lot of youth in our area have not been exposed to other cultures or people from other cultures.

A 30-45 minute presentation for youth that is exciting and adequately conveys the importance of global citizenship. We do STEM-related activities for this duration that youth love, but we have difficulty engaging youth in a short-period in global citizenship. Also, prioritizing. This always falls to the bottom of my "To Do" list and I get to it if I have time.

--the naturally selfish outlook of most teens --Appalachia can be somewhat "provincial" and even exploring national issues can be a challenge

I teach mostly preschool students and do not usually introduce anything global to them. 


\section{Q23 - Please list up to five program strategies you have used to implement global citizenship education in your programming?}

Camp programs that are globally respresented, Including small facts about where different items originate, physically show different items that represent different cultures (Flags, clothing, foods.)

Global village role playing. Urban Immersion service learning program to Washington DC. Teen experiences with intentional mix of youth from urban, rural, suburban and multiple socio-economic groups. Global monthly themes for after school programming with youth teaching parents as the capstone.

part of an in-school lesson; promoting global 4-H initiatives via Facebook; sharing with parents who could have an interest in hosting an IFYE; sharing FB posts related to global 4-H

N/A

Career Education/Workforce, Diversity Education, Softs Skills (Respect of other cultures), and also by working with Junior Achievement as a partner in Global Citizenship Education.

promote opportunities to volunteer / complete service projects, engage youth in discussions about local, state, national events, google expedition / VR to allow opportunities to explore different locations,

1) Using a bottom-up approach, where you move from the local to the global and demonstrate the connection to their daily lives. 2) Integrating a global connection into other subject matter.

Activity as part of another program; club lesson

intercultural understanding activities. technology (e.g. skype) to connect local youth to youth in other countries.

dietary traditions

Global examples, offering opportunities to get involved globally, addressing different cultures and heritages in the county.

Provide families with opportunities to participate in international exchange programs and support families who choose to do so. Provide local youth information on international travel opportunities provided by other entities in KY 4-H. Target KUNA youth at local schools for participation in 4-H leadership programming. Have provided multicultural club and project experiences including language, dance, dress, and food. 
Military club diversity night, 4-H Day at the Capitol, Sharing international opportunities and opportunities to host exchange students, Community service projects/drives

direct insertion of food origins while teaching

Hosting exchange students and discussing their viewpoints/experiences while I am teaching.

Guest speakers at camp, Guest speakers at schools,

Connect with community partners, seek funds through local non-profits.

Skillatons, posters, newspaper articles, radio programs, educational brochures

Youth involved in 4-H international programs have spoken to groups of 4-H agents and volunteers to encourage and motivate them to promote the programs. Motivated teens to work to to raise money for programs. International visitors have spoken to groups of 4-H youth, agents and volunteers encouraging participation.

Study a country each month; use WeConnect Curriculum; use Diversity the Source of Our Strength Curriculum; utilize guest speakers with experiences in other countries to compliment lesson plans for global citizenship programming

Newsletter lesson plans personal contacts social media

Travel, class, comunication, camp, sports

N/A

Extension taught Christmas Around The World at the local elementary school before Christmas break.

NONE

Involve individuals from other cultures and countries; non-fiction books

Skill-a-thons combined with cryptology

food, international exchange opportunities

introduction of international foods

promotion of hosting international students, teaching about agriculture in other countries 
Working with Social Studies teachers, geared the lessons towards developing leadership and personal development skills

Introduce different foods, activities related to other countries, Offer opportunity of different backgrounds

1. Compare and contrast with a global partner, pick specific examples to provide perspective on differences. 2. Seek community leaders with cultural awareness to offer assistance in delivery. 3. Develop, to the best of one's ability, age specific approaches to programing.

1. Having our international participants be educators; 2 . Working with local services to have interpretation on site for programs; 3. DIverse communication platforms to reach a variety of audience members

Workforce development, career planning, internaitonal economics topics, reading clothing labels

N/A

Life experiences outside of the county.

I haven't had many opportunities to implement global citizenship in my programming, but I've focused on the skill a thon curriculum that are available to us. The youth that I have presented to seem to really enjoy the little activities.

N/A

Camp session or guest speaker; Global challenge/World Food prize lesson as a school enrichment program in HS classes; LABO exchange hosts and travelers;

Cultural awareness

I have had exchange students from Japan speak with local civic groups.

Created publications that include a global perspective, such as Global Gourmet, or leadership activities that ask youth to think about global impacts

Sharing origins of plant names and native habitats, sharing overseas experiences with volunteers, teaching about new vegetable introductions originating from other other countries,

research, teen council, hands on activites, cooking

Basic classroom programs and 4-H camp

Not really applicable to me as a SNAP-Ed Program Assistant. We follow a set curriculum 
I use multicultural stories to read to children in class

Just bringing up culture, tradition and available foods in other countries.

pictures, curriculum and activities specifically geared toward children, guest speakers

Collecting items to be donated to causes in other countries, incorporating cultural foods into food \& nutrition programming

4-H exchange programs

none

School programs; Camp Assemblies; Camp Themes; Camp Classes; Afterschool Programs

I like to let people know where certain plants originated (every plant is a native plant), since I traveled to Holland and Europe, I pass along how much further along other countries are in their horticulture breeding/research/etc than the US is

weaving grade 3 social studies SOLs into nutrition (food culture, how environment affects which foods a culture grows in whatever they are studying- China, Greece, Mali, Rome, etc))

School Clubs, after school clubs, foods programs, camping programs

N/A

Music program, Trip to Russia, 4-H alumni giving programs of opportunity in 4-H and in college, Foods of other countries

Hosted IFYE program, hosted a youth from Japan, worked with international programs at State Camp, assisted with global citizenship weekend events

global skill-a-thons, global service projects, camp education

N/A

(1) Relating topics in lessons to bigger picture gloabal issues (ex. food shortage). This is really the only techniq

Don't know.

Service learning-sole hope, exchange students, videos

N/A

Including many examples when possible 
--hands on lesson that placed youth in the shoes of another person was useful

Guest speakers from other countries. Encourage 4-H families to host a LABO youth.

discuss it with teens, design curriculum, help to implement high school 4-H trip abroad

International Agriculture Day

Teaching about foods in other cultures, integrating tolerance into teaching programs, including diversity in teaching and service programs, conducting research on other people's feelings on people in poverty

Trips to Canada; hosting Japanese youth in my home from Japan and Okinawa through 4-H/LABO and Peace USA; learning about European agriculture after he led a group overseas; utilizing international summer camp staff in camp programming.

One lesson allows me to teach what other people do in other countries while we do it our way. I use this lesson to help them realize that there are many ways to prepare foods, dress and speak and it is interesting to meet others.

make it relevant to youth; show how all youth have similiar experiences

organizing, implementing, fundraising, evaluating,budgeting

IF students are willing to share, have students who have experienced different cultures share their experiences (ie, some students will volunteer 'we traditionally eat _ for Christmas' 2. Helping students understand where their foods come from. What fruits and vegetables are local and foods come from that are not local. 3 . When working with adults, try to understand what foods they are familiar with and how they can find those foods locally for an economical price.

Bringing it up at planning meetings (when no one else does!)

IFYs. Help when Haiti and Guatemala had needs.

NA

n/a

Hands on activities, discussion, sharing

We offered a SPIN Club for International Cooking our focus was food from other countries. Last year we hosted the international student for CEOS from Cameroon and did a program at a local elementary school with her. A few years ago we had a 4-H international student and his chaperone from Japan do a program offered to the public at our office.

N/A 
curriculum, project-based learning, teacher education, presenters

Workshops on culture/diversity, hosting IFYE exchange students mulitiple years with volunteer families in my 4-H program, conducted trainings (3 different trips) in Senegal to develop 4-H program, incorporated diversity \& cultural awareness in to teen trainings, hosting group of 14 from Senegal for two weeks of camp this summer (2019) and offering special classes/workshops to further promote cultural exchange for all participants

None.

With FNP our programming is pretty focused on the USDA and SNAPed's mission so I don't always ahve an opportunity to infuse global perspectives into my professional life.

Discuss my personal experiences, tell stories of the people I have met abroad, communicate about experiences via pictures.

1. Out of country leaders share their experiences; 2.Share experiences with travel;

Students are exposed to broad concepts of global citizenship such as sustainablility andconservation of natural resources. Students are also exposed to multicultural recipes and books are often used to enforce concepts. For example, during Rethink your Drink week, one of the activities features the National Geographic book "A Cool Drink of Water " which showcases the importance of water/conservation both here in the United States and throughout the world.

none

N/A

Using examples of similar issues in other countries, Giving first hand accounts from friends from other countries, using program materials that focus on other countries, having volunteers share experiences they have outside of the country, and talking about current issues in the news in discussions about global economy.

talking points during other program with teens, promotion of the international 4-H programs to my county

Offering cooking camps that teach about different cuisine and different regions, discussing gardening options and designs that might be used in different regions of the world, offering and encouraging youth to participate in study abroad options and exchange programs, encouraging families to host international exchange programs.

History, Geography, international cultures, Communication -social and media, community service 
test

international foods, film, music

Create global context in year lesson, bring in guest speakers or use technology to highlight global people

books on the topic, discussion, service activities, serving food from other countries, working with globally involved groups

teaching about cooking/nutrition from other regions, encouraging child care providers to expand their cultral expose within their classroom to include holidays from other countries, music from other countries, books, etc.

We have used: Children's literatures, guest speakers from local universities, communitiy service projects

I often teach foodways of other countries, as well as cultural differences.

N/A

Inviting others to come and speak about their culture,

1. Personal Experience from Study Abroad trips 2. Use of my Spanish Degree 3. Current Affairs in News 4. Incorporating books with diversity as a focus

I have not done global programming.

Having materials in Spanish, Contacting local organizations that help to educate Hispanics and other minorities, partnered with local organizations that deal more with this population, Getting resources from the Kentucky State University about interpreters and information in Spanish

Camping Environment, club programming, volunteer training, hosting exchange International Examples, Cultural Examples, Cultural Activities where they apply, etc.

Teach where fashion comes from and the centers in the world that lead that industry Adding global stories and data into presentations, deliver presentations about my trips by showing photos and videos, summer camp dedicated to global citizenship

hosting exchange youth, food and culture exploration, virtual field trips

food, music, stories, guest speakers,

sharing personal experience, learning from the experiences of others, focusing on cultural differences as a way of acceptance, 
$\mathrm{Na}$

Camps, Clubs, School Enrichment

foods and nutrition: tasting cultural fruits and vegetables; exploring food customs from other cultures; how to say "party" in other languages; Leadership: sharing results of international leadership studies; greetings and acceptable welcoming behavior in other cultures.

asking individual to present to groups, encourage members to participate in international exchange program, using existing curriculum

hiring international staff for camp, cultural workshops for youth, emerging issues forum

Multi-cultutal dinner for community.

cultural awareness with food

None

1. Incorporating into camp as a class or assembly, 2. identifying globally-minded teachers in my county and provide in-school enrichment to their students, 3. Provide international classes on different topics - open to the any youth. 
VITA

DENIS M. SCOTT

2007: State University of New York at Binghamton

Master of Public Administration

Binghamton, NY

2004: Frostburg State University

Bachelor of Science

Frostburg, MD

Majors: Political Science, Sociology

2001: Allegany College of Maryland

Associate of Science

Cumberland, MD

Major: Political Science 